\title{
Development of Swiss Biotechnology Beyond the Biopharmaceutical Sector In memoriam Prof. Dr. Oreste Ghisalba (1946-2018)
}

\author{
Hans-Peter Meyera and Oleg Werbitzky ${ }^{\mathrm{b}}$
}

\begin{abstract}
Although diverse, the potential business opportunities for biotechnology outside the biopharmaceutical market are very large. White biotechnology can offer sustainable operations and products, while investments tend to be lower than those in red biotechnology. But a number of bottlenecks and roadblocks in Switzerland must be removed to realise the full potential of white biotechnology. This was also the point of view of Oreste Ghisalba, who wanted to be part of a new initiative to facilitate the creation of additional business, new processes and new products. This initiative requires the identification and the use of synergies and a much better cooperation between academia and industry through targeted networking. Unfortunately, we must carry on with this task without Oreste, whom we will miss for his deep knowledge and friendship.
\end{abstract}

Keywords: Bio-based · Fine chemicals · Industrial biotechnology · Swiss economy · White biotechnology

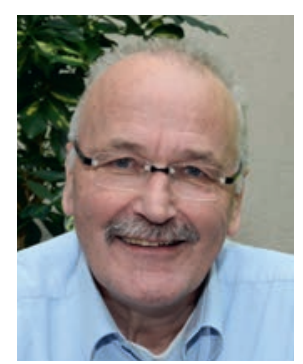

Hans-Peter Meyer holds a $\mathrm{PhD}$ in microbiology from the University of Fribourg (Switzerland). He spent three years postgraduate and postdoc studies at the STFI in Stockholm (Sweden), the University of Pennsylvania and Lehigh University in the USA. In 1982 he joined Prof. Armin Fiechter's team as group leader \& lecturer at the Swiss Federal Institute of Technology in Zurich before joining Lonza in Visp (Switzerland) in 1986. He retired from Lonza after almost 30 years in industry in different positions in $\mathrm{R} \& \mathrm{D}$, production, marketing, and strategic projects. He was one of the first members of the early Lonza team that implemented biotechnology in the company. He still lectures at the Applied University of Western Switzerland, is a Member of the Swiss Academy of Technical Sciences, an expert at the Swiss National Science Foundation Bridge Proof of Concept programme, and partner and board member of Expertinova AG.

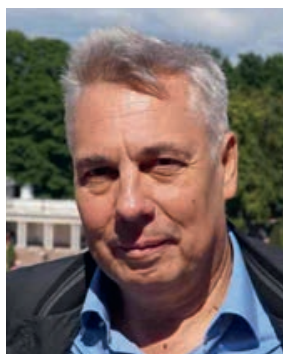

Oleg Werbitzky holds a doctorate in organic chemistry from the Technical University of Munich (Germany). He spent three years of postdoc studies with a grant from the BMBF (Federal Ministry of Education and Research, Germany) at the Institute for Biochemistry at Technical University of Darmstadt (Germany). In 1990 he joined the chemical R\&D department at Lonza in Visp (Switzerland). During his time at Lonza, he developed over 20 industrial processes, including several enzymatic and microbial biotransformation processes, and led several strategic initiatives related to the implementation of new technologies. In 2012 he joined JTI in Geneva (Switzerland) as a VP for Emerging Products. He is a partner at LOGSCALE venture partners and Managing Director of NC Health Sciences since 2015 .

\section{A Short History of the Swiss Biotechnology Industry}

The Swiss pharmaceutical and chemical industries have been responsible for almost half of the country's exports for many years and biotechnology plays an important role in all of this. Relative to its size, Switzerland is probably the global number one in red biotechnology, that is, the use of biotechnology in the medical and pharmaceutical industries, and health preservation. The success story goes back to the $18^{\text {th }}$ century.

Population growth and the prohibition of employment as mercenaries by the protestant canton of Zurich led to high unemployment in rural areas. The industrialization of the larger Swiss cities and the resulting generation of wealth first started in the $17^{\text {th }}$ century, but rural areas remained destitute well into the $18^{\text {th }}$ century. To provide work for the rural population, home-based work in the textile sector was promoted. Thus, Switzerland's industrialization began with the production of textiles in rural areas and as a result this triggered the start and expansion of the machine, the chemical, the food product, and ultimately the pharmaceutical industries. Industrialization also resulted in changes in agriculture. The Swiss watch industry is the exception. It was founded during the $16^{\text {th }}$ century and resulted from Jean Calvin's reforms that banned the wearing of jewellery. This forced the goldsmiths and jewellers to turn to a new, independent craft: watchmaking, where the know-how was introduced by Huguenot refugees from France. By 1790 Geneva was already exporting more than 60,000 watches per year!

The first textile machines were imported from England in 1764, but the continental blockade that started in 1806 during the Napoleonic wars made the further import of machines impossible. In accordance with the motto "never miss a good crisis", the Swiss started to manufacture their own machines and the Swiss machine 
industry was born with Escher \& Wyss (1805) and Johan Jacob Rieter (1810). Later Sulzer and SLM were created as spin-offs from a foundry. Saurer was also an early textile machine manufacturer, which later changed to automobiles and trucks, producing its first truck in 1896.

With the advent and expansion of railway and maritime transport, Swiss agriculture was plunged into a crisis in the second half of the $19^{\text {th }}$ century, as ever cheaper cereals were imported from Eastern Europe and overseas. Swiss farmers responded with co-operatives and the export of higher value agricultural products such as cheese, condensed milk and the famous Swiss chocolate. Cailler (1819) and Suchard (1826) made Swiss chocolate world famous. Rodolphe Lindt developed a new conche method to produce chocolate that melts on the tongue without its former 'sandy' taste. With increasing industrialization, the first convenience food products that catered to the needs of families working in factories appeared. The first fast food soups by Maggi and Knorr were produced in Germany and later acquired by Nestlé, whose founder Henri Nestlé started with baby nutrition based on milk, sweeteners and flour in 1866. With the merger of Nestlé's factory in Vevey with the Anglo Swiss Condensed Milk Co. (Cham ZG) in 1905, Nestlé became the big multinational company we know today.

Daniel Frey founded the first Swiss chemical factory in Aarau in 1804, but the industry only really began to blossom 50 years later. Ciba (Chemische Industrie Basel) was founded in 1859 and Sandoz in 1885 . The Geigy family had married into silk manufacturing and began with the extraction of substances for dyes. They were also the first in the drug business as early as 1758 , but the core business of Geigy, Ciba, Sandoz and other chemical companies at that time was the production of textile dyes by organic chemical synthesis. This know-how in organic synthesis was the basis for the synthesis of small molecule pharmaceuticals. Hoffmann-La Roche, founded in 1896, was the only company that specialized in pharmaceuticals from the beginning.

A second series of events was also decisive for the development of chemistry at the end of the $19^{\text {th }}$ century in Switzerland and Europe, where there were hydroelectric power stations. Electric arc furnaces produced calcium carbide with graphite electrodes at around $2000^{\circ} \mathrm{C}$. Calcium carbide, which forms acetylene in the presence of water, was used in carbide lamps. However, as soon as electricity could be transported over long distances by high voltage AC, electric light replaced calcium carbide. Consequently, manufacturers had to redirect their activities, for example by changing from the original product to calcium cyanamide, acetaldehyde and later to a whole new family tree of organic chemicals - a path followed by Lonza. ${ }^{[1]}$

The Swiss School Council decided in 1976 to establish the development of biotechnology primarily at the ETH Zurich. On 25 November 1981, the same council decided to establish the first Institute of Biotechnology in Switzerland at the Hönggerberg campus of the ETH in Zurich, with Professor Armin Fiechter as its first professor and director starting early 1982. From this start, a broadly-based academic community was built. The topics and key players are outlined below.

\section{The Current Situation}

Biotechnology is a key asset to the contemporary Swiss economy. Relative to its size and population, Switzerland is the global number one in large and small molecule pharmaceuticals. The Swiss Biotech Report for 2018[2] shows that chemical exports in 2018 were in the lead with CHF 105 billion. CHF 84 billion $(80 \%)$ were pharmaceuticals. Besides the export statistics, the SMI (Swiss Market Index) is a good indicator of the life science sector. This blue-chip index was introduced 1988 and is composed of 20 companies. At the end of 2019, six of these companies had a direct relation to the life sciences (Alcon, Givaudan, Lonza, Nestlé, Novartis, Roche). Three of them (Nestlé, Novartis,
Roche) are among the top 50 global companies in terms of market value.

Biotechnology affects almost every area of life today and is used in diverse markets with a wide variety of products and processes. For a structured overview, one could distinguish according to markets, production methods, regulatory or other criteria. However, a common method is the 'five colour code' of biotechnology red, white, green, grey and blue.

Red biotechnology is the use of biotechnology in the medical and pharmaceutical industries. It targets a specific but profitable market with a few, well established process technologies. Monoclonal antibodies generate about half of the annual sales in this sector.

Green biotechnology is the application of genetically modified plants. Switzerland prohibits plant GMOs. A moratorium on the cultivation of Genetically Modified Organisms (GMO) has been in place since 2005, is valid until 2021, and prohibits their use in agriculture, silviculture or horticulture. With the new recently elected parliament the moratorium will certainly be renewed. This is a lost opportunity for Switzerland.

Grey biotechnology is the treatment and remediation of water, soil and air, and is a thriving branch with well-established academic and industrial activities.

Blue biotechnology is the sourcing of products from the marine environment. While Switzerland is not very active in the area, blue biotechnology is still of relevance to the pharma industry, not from a strict sourcing point of view, but as a source of new molecular structures of interest for pharma.

Finally, white, or industrial biotechnology, the main topic of this article, is characterized by the numerous and very different markets it addresses and the very different product types. This is associated with a variety of partly unique process technologies. However, the white biotech toolbox is chronically lagging behind. This can be explained by the heterogeneity of the markets addressed and the products produced. Despite this heterogeneity, well over $50 \%$ of the global annual sales in the white biotech sector are accounted for by one category: biofuels. ${ }^{[3]}$ Taking Porter's Five Forces as a basis for a comparison, white biotechnology sector products also face a higher intensity of economic competition. ${ }^{[4]}$

- The threat of entry from competitors is high because of lower technical barriers.

- The power of suppliers is limited because of many (chemical) supply alternatives.

- The power of buyers is considerable.

- The threats of substitutes from organic chemistry and extracted products can be turned into an advantage for biotechnology if higher sustainability can be achieved.

- Competitive rivalry is not as high with a much smaller number of research institutions involved in white biotech.

Unfortunately, the high cost pressure and low barrier of entry into the white biotechnology sector does not allow for radically new and innovative methods and processes in most cases. Consequently, industrial actors are enticed into incremental innovation and changes.

Recent biotech history has been marked by a continuous refocus on core competencies and high-value products. Between 1970 and today this resulted in entirely new companies with new landscapes and structures. Some companies such as Lonza have reinvented themselves over the last 40 years. Today, the Swiss chemical industry is focused on life science and chemical specialties, so that the world-wide sales of the top ten Swiss companies are split as follows: pharmaceuticals $63 \%$, fine and specialty chemicals $13 \%$, crop protection $9 \%$, diagnostics $8 \%$, vitamins, flavours and fragrances $7 \%$.

Who are these Swiss chemical companies today? We estimate that there are about 900 chemical companies in Switzerland, 
which is not many compared to the US, although this is a country about forty times bigger in terms of GDP and population. The US chemical industry has about $10^{\prime} 000$ firms, ${ }^{[5]}$ producing more than 70 '000 products, more than $\$ 800$ billion in revenues, and affecting more than $96 \%$ of all manufactured products. Many Swiss chemical companies are micro companies and SMEs active in the sales and distribution of chemicals, and only a small fraction are actually manufacturing or developing products and processes. In addition, the label 'bio' or 'biotechnology' is often used although the activity of the company has nothing to do with biotechnology. In some cases the term biopharmaceuticals is used for small molecules. We speculate that the companies want to improve their image by using the term 'biotech', which may sound technologically more advanced and so more attractive to investors.

\subsection{Companies}

The authors screened for Swiss companies that have activities in the white biotechnology and chemical sector or companies that could have a link with biotech due to their current activities or product portfolio. The list is a random selection without any claim to completeness.

ABAC R\&D (http://abac.ch) Founded in 1999, ABAC is active in the development and marketing of innovative, mainly yeast-derived products such as glucans and mannoproteins for the food, cosmetic, wine, and feed industries. Heterocolloid systems, a combination of insoluble dietary fibres (e.g. glucan) and soluble polymers (e.g. pectin) are used for the delivery of bioactives in human and animal nutrition, cosmetics and medicine. The company has expertise in yeast biotechnology with in-house small-scale fermentation capacities and collaborates with customers and universities for $\mathrm{R} \& \mathrm{D}$, pilot production and efficacy studies.

Anteis SA (www.anteis.com) Anteis SA is now Merz Anteis. Founded in 2003, the company was acquired ten years later by Merz from Frankfurt, a company with 3'000 employees specializing in the development, manufacture and commercialization of biomedical products in the area of aesthetics. Anteis SA, located in Plan-Les-Ouates, is an FDA-approved manufacturing site for hyaluronic acid fillers. The core competence of Anteis is hyaluronic acid in combination with biopolymer transformation and medical injection devices.

Archroma (www.archroma.com) Headquartered in Reinach and privately owned by SK Capital, Archroma delivers dyes and specialty chemicals with 3'000 employees and 26 production sites. The roots of the company go back to Sandoz as the firm was created as a spin-off from Clariant in 2013. Clariant itself was a spin-off from the Sandoz chemical business during the formation of Novartis. With Earth colors ${ }^{\circledR}$ Archroma created a line of dyes that are synthesized from non-edible agricultural and herbal waste. Besides offering dyes for clothing, textiles and leather, Archroma is also active in packaging paper, tissues, towelling, printing, and writing.

Aschem GmbH (www.aschem.ch) Fine chemicals company founded in June 2018 and based in Basel, with R\&D and production centres in Switzerland and China supplying markets with $\mathrm{mg}$ to ton quantities. Aschem $\mathrm{GmbH}$ describe themselves as a synthesis designer for the production and commercialization of building blocks for drugs, and for providing nanomaterials related services. The services include design of the synthetic route of compounds plus data analysis, preparation of compounds or API with or without cGMP standards, the synthesis of challenging chiral compounds, and the synthesis of bio-conjugates and much more. Most work is presently done in China with industrial and academic partners.

AVA Biochem (www.ava-biochem.com) AVA Biochem, based in Muttenz, Switzerland, produces the furan-based platform chemical 5-hydroxymethylfurfural (5-HMF) from renewable carbohydrates. An industrial scale plant (6'000 tons per year) is currently in the planning stage. The functional groups make 5-HMF a versatile furan building block. Promising applications of 5-HMF are as a replacement of fossil-based formaldehyde, and as a precursor for the synthesis of other platform chemicals such as furan-2,5-dicarboxylic acid (FDCA), which can replace fossil-based terephthalic acid. Further downstream products from 5-HMF are diformylfuran (DFF), bishydroxymethylfuran (BHMF), and bishydroxymethyltetrahydrofuran (BHMTHF), along with their corresponding diamines. Operating out of its Muttenz, Switzerland, pilot plant, AVA Biochem can currently supply up to 5 tons per year of 5-HMF in aqueous solution as well as highly purified crystalline 5-HMF. The company participates in the Horizon 2020 Smartbox project for selective enzymatic modification of aromatic compounds.

Axpo (www.axpo.com) Axpo is Switzerland's most important producer of renewable energy. Axpo Biomass is Axpo's branch practicing dry fermentation of organic waste in 15 fermentation plants, recycling biowaste from over 2'500 customers. Up to 1 '000 kWh energy and $900 \mathrm{~kg}$ of natural fertilizer can be produced with 1 ton of biowaste. Axpo Compogas AG offers entire disposal and recycling services for organic wastes.

AZAD (www.azad.ch) Azad was originally established in 2000 to handle the API marketing and sales activities of Cilag. AZAD concentrates its activities on difficult to produce (process, patent situation) molecules. The company offers its services generally to the pharma sector. Synthesis and processes are developed in cooperation with external partners in Switzerland and abroad under the auspices of AZAD's chemists.

Bachem (www.bachem.com) Bachem is a listed, technology-based company focused on peptide chemistry founded in 1971 by Peter Grogg. The manufacturing of peptides under GMP for medical use started in 1978. In 1997 Bachem obtained its FDA approval. Over the years, there were several site expansions to increase capacity. Today, Bachem employs over 1'200 people at six sites in four countries and on three continents. A comprehensive catalogue of biochemicals and exclusive custom syntheses for research labs complete the service portfolio. The key figures for the fiscal year 2018 were: sales CHF 282.5 million, EBIT CHF 54.8 million generated with 1,097 FTEs. Sales per employee were 0.27 million. In an interview published in the Bachem Annual Report 2013, the Bachem CTO D. Erne strongly advocated for chemical peptide synthesis for peptides up 100 amino acids. Bachem has reported the successful chemical synthesis of the 166 amino acid glycosylated peptide interferon $\beta-1 \mathrm{a}$ in collaboration with Japanese researchers. According to Bachem's CTO, recombinant technology is unsuitable for producing shorter peptides on cost grounds. Moreover, he claimed that it is not possible to produce peptides by recombinant technology if they contain unnatural amino acids or have undergone any other structural modifications. Bachem Holding AG and Berna Biotech AG founded Pevion Biotech AG for the production of vaccines based on the combination of peptides and virosome technology. However, Bachem sold their Pevion Biotech AG shares in 2014.

BASF Schweiz AG (formerly Ciba Specialty Chemicals, www.basf.com) Ciba (Chemische Industrie Basel) was a chemical company based in and near Basel, Switzerland. It was formed during the creation of Novartis, as the non-pharmaceuticals elements were spun out of Novartis in 1997, following the merger in the previous year of Ciba-Geigy and Sandoz that created Novartis. Ciba developed biocatalytic processes, for example for the production of the photoinitiator Organox $245^{\circledR}$ with an immobilized enzyme in a chromatography column. Ciba was able to run the process continuously for six months. ${ }^{[6]}$ In 2008, Ciba was acquired by the German chemical company BASF and, in April 2009 , integrated into the BASF group. Ciba AG initially continued to trade under the old name, but was renamed BASF Schweiz AG in March 2010. Ciba was one of the founding members of the Swiss Industrial Biocatalysis Consortium (SIBC). 
Bioma SA (www.bioma.com) Bioma SA was founded in 1990 and is developing and manufacturing chemical-free products for a range of applications (e.g. agriculture, bioremediation, food preservation) with 20 employees. Product examples are specific bacterial-enzymatic formulations that may be combined with vegetable extracts to optimize microbiological transformations, promote the indigenous microbial population and maximize yield and quality. Production and supply of the bacteria and enzymes for the formulations is presently done by third parties.

Biosynth Carbosynth (www.carbosynth.com) The company was created by the merger of Biosynth and Carbosynth, with headquarters in Switzerland and manufacturing laboratories in Switzerland, UK, Slovakia and China. The company offers a wide range of products such as biochemicals, chemical intermediates, APIs and natural products for the life sciences. They offer custom synthesis or extraction according to ISO and GMP standards in facilities near Oxford UK. As a niche API manufacturer they operate reactors between $50 \mathrm{~L}$ and 2'500 L in Switzerland. Enzymatic reactions are possible and Biosafety Level 2 laboratories are available. Their affiliate in Nanjing, China is specialized in process development, while scale-up and small-scale production is carried out in Switzerland.

Carbogen Amcis (www.carbogen-amcis.com) Carbogen Amcis was founded as Amcis in Bubendorf Switzerland as a spin-off of CIS Pharma AG in 1982. In 2000 Solutia acquired two companies, Carbogen and Amcis AG and combined them into one company called Carbogen Amcis. This newly formed company was then acquired by Dishman Pharmaceuticals and Chemicals Ltd six years later. The production site in Bubendorf, which was opened in 1987, offers the development and cGMP manufacturing of highly potent APIs including antibody drug conjugates with up to $100 \mathrm{~kg}$ scale for ultra-potent toxins. Another facility in Aarau Switzerland opened in 1994 and provides a wide range of technologies such as solid-state analysis, chromatography, isolation and analytical services.

Cerbios (www.cerbios.ch) Cerbios is a privately held company with headquarters in southern Switzerland (BarbegnoLugano). Cerbios specializes in the development and manufacture of chemical and biological APIs and offers third party CDMO services for APIs, HPAPIs, Biologics and ADCs. For the latter Cerbios, AGC Biologics and Oncotec formed a collaboration called Proveo (http://www.agcbio.com/proveo/home) in 2015 to provide services for antibody drug conjugates. The company has also developed and manufactured probiotics for human and animal health since 1976. Cerbios also established its own cell line expression platform ( $\mathrm{CHO}$ derived) that is available for third party recombinant protein development and manufacturing projects. Cerbios' facilities are located in Barbengo-Lugano (TI) and in Couvet (NE) under the name of GMT SA Fine Chemicals. Biocatalytic steps are evaluated in API process development, such as that for the process for the formylation of tetrahydrofolic acid with a transferase. ${ }^{[7]}$ Cerbios is also FIT member (Farma Industria Ticino, www.farmaindustriaticino.ch/) founded in 1980 as a private organization with 31 member companies, a combined workforce of 2'900 employees and an annual turnover of 1.7 billion Swiss francs.

Chemgo (www.chemgo.ch) Chemgo is a Swiss company founded in 2019 through the fusion of Stehelin AG and Chemgo Organica AG. It is one of the many companies active in the distribution of fine chemicals for the life sciences and related industries. The company is Swiss Medic audited and authorized for GDP (Good Distribution Practices).

Cilag (www.cilag.ch) Cilag (Chemical Industrial Laboratory) was established in 1936 and the first product was Pyridacil ${ }^{\circledR}$, an azo dye derived from pyridine that is still used for the disinfection of kidneys and the urinary tract. Since 1959 Cilag became part of Johnson \& Johnson and is now a unit of Janssen, the pharma- ceutical division of Johnson \& Johnson. With 1'200 employees, Cilag AG is one of the largest manufacturers in the Swiss (small molecule) pharmaceutical industry.

Cimo (www.cimo.ch) CIMO or Company Industrielle Monthey is a large integrated chemical manufacturing site with over 2000 employees. The site goes back to 1904 with the foundation of the Société des Usines de Produits Chimiques. The 400 employees of Cimo manage the site, which is shared by BASF, Huntsman and Syngenta. The products are organic chemicals such as pigments, polymers or crop protection products. There are no biotechnological activities on the site.

CIS Pharma AG (www.cis-pharma.com) The company was founded in 1952 by Werner Schäfer in Basel as CIS Pharma. The company offers bio-inspired polymers potentially used for tissue regeneration and $3 \mathrm{D}$ printing, $\mathrm{ADC}$ drug carriers or contact lenses. In 1983, Amcis AG was spun out from CIS Pharma AG. CIS Pharma developed plant stem cell technology based on Edelweiss (Leontopodium alpinum), a plant that is highly resistant to environmental stress. Antioxidants, radical capturing agents and other protective compounds from Edelweiss stem cells are the basis for an anti-aging skin care treatment. Another CIS Pharma product is Cellophil $^{\circledR}$, a biomaterial based on bi-functional amino acids for bio-medical use.

Clariant (www.clariant.com) is a public company founded 1995 as a spin-off from the chemical business of Sandoz during the formation of Novartis, with business units for additives, catalysts, functional minerals, industrial \& consumer specialties, pigments, oil and mining services. There are 18'000 employees that generate group sales of CHF 6.62 billion. Their life science-related products include personal care chemicals, crops, and the biocides business. Clariant acquired Süd-Chemie AG and their Sunliquid process and plant in Straubing (Bavaria) for the production of cellulosic ethanol in 2011. The associated know-how can also be used for other bio-based chemicals. Roughly $300 \mathrm{~L}$ of anhydrous ethanol are produced per ton of biomass. Clariant have a partnership with GEVO, which uses ethanol as feedstock for propylene, and isobutylene. Plans exist to license the biotech Sunliquid ${ }^{\circledR}$ process for $25^{\prime} 000$ to 50’000 tons of cellulose bioethanol with installations in Poland and Slovakia. Liquebeet ${ }^{\circledR}$ is a sugar beet-based carbon and energy source for fermentations. Clariant also introduced 25 organic pigments specifically for biodegradable polymers. The company has an open innovation platform with two topics: personal care and smart packaging. Clariant is presently in the process of reorienting the company to focus on personal care chemicals and deicing products. Clariant and French Plant Advanced Technologies (PAT) entered a partnership for the production and distribution of plant-based products for personal hygiene.

Corden Pharma (www.cordenpharma.com) Corden Pharma is a full-service CDMO for the production of APIs, drug products, and associated packaging services, and consists of 8 cGMP facilities and one R\&D centre. The facility in Liestal, Switzerland (Corden Pharma Switzerland) offers process development and cGMP manufacturing for small molecule APIs, intermediates and chiral building blocks, with special expertise in synthetic lipids, carbohydrates and conjugates thereof. Corden Pharma Switzerland does not use biotech tools at their site in Liestal, but the parent company ICIG recently acquired a former Sandoz site for the production of 7-aminocephalosporanic acid (7-ACA), and integrated it as Corden BioChem near Frankfurt Germany with a total fermenter volume of 3'000 $\mathrm{m}^{3}$. However, production of this critical building block was discontinued at the end of 2017, but biotechnology is still used at this site.

Debiopharm Group (www.debiopharmagroups.com) was founded in Valais in 1979 by Rolland-Yves Mauvernay on the basis that many potentially useful drugs do not make it through clinical trials to the market, because they are abandoned too early. 
Today using the collective intelligence of 300 employees and 400 external consultants, the company has developed a pipeline of 20 products with a focus on oncology.

Dottikon Exclusive Synthesis (www.dottikon.com) was founded in 1913 as the Schweizerische Sprengstoff-Fabrik AG (SSF) for the production of explosives. From the 1930s to the 1970s the SSF developed processes for nitration, hydrogenation and oxidation leading them to the chemical intermediate business. In 1987, the Ems Chemie Holding AG purchased the company and changed its name to EMS-Dottikon, but it was spun-off in 2005 and became Dottikon Exclusive Synthesis. Listed on the SIX (Swiss Exchange), the SME is a CMO specialist for hazardous reactions with more than 600 employees. 93\% of all sales of over CHF 158 million were generated with pharmaceutical products and APIs. The company profits from the fact that pharmaceutical companies outsource production to third parties. In order to reduce risks, the company also develops innovative products in the performance chemicals sector to cover unmet needs outside of the pharma market. Based on increasing orders, the company is continuously investing and expanding its capacities. The core technologies include metal-organic reactions, but enzyme catalysis is not part of their toolbox. Dottikon Exclusive Synthesis has more than 40 years of experience in the production of APIs and is FDA and EMA approved. As a specialist for hazardous reactions they are equipped for HAPIs (Highly Active Pharmaceutical Ingredients) and HPAPIs (Highly Potent Pharmaceutical Ingredients) with OEL (Occupational Exposure Limits) of $<1 \mu \mathrm{g} / \mathrm{m}^{3}$.

DXC RT AG (www.dxc-rt.com) DXC RT AG offers R\&D services that range from feasibility studies to plant biomass production. Plant tissue cultures are established and optimized to obtain plant biomass with the required quality. Hairy roots, adventitious roots and plant cell cultures up to production scale are used by the cosmetic, nutritional and pharmaceutical industry. DXC RT AG can produce up to 2 tons of fresh biomass of different species at their production plant in Aesch BL and are working to scale up their production to 5 tons per year. They operate bioreactors for hairy roots up to $100 \mathrm{~L}$. They work with partners for plant cell culture production.

Embion Technologies (www.embiontech.com) is a spin-off from the EPFL in Lausanne. Functional ingredients are extracted from plant biomass with a patented technology and used for the formulation of nutritional ingredients that confer health benefits. Fibre, protein and other macromolecules are extracted using an ionic catalyst in a low pressure/moderate temperature process from lignocellulosic biomass residues. The fibres extracted in the form of oligosaccharides are potential prebiotic ingredients used in feed, food, cosmetics, and pharmaceutical formulations.

Evolva (www.evolva.com) Evolva was founded in 2004 and shows how challenging it can be to establish a successful technological platform in white biotechnology. Evolva offers Saccharomyces cerevisiae as the platform genetically engineered organism for the production of natural products. End-products include nootkatone (NootkaShield ${ }^{\mathrm{TM}}$ ), stevia (Rebaudioside M), vanillin, saffron, resveratrol, carmine, sandal wood, ambergris, opiates and others for which Evolva has successfully developed genetically engineered yeast strains. Over the years, the company also worked with many partners such as Ajinomoto, BASF, Cargill, IFF, Roquette, Takasago, Firmenich, Givaudan and others. Evolva shares were traded at CHF 37 at peak value. Today the share price is only around 28 cents, this despite of a successfully working technology platform.

Expertinova AG (www.expertinova.com) Oreste Ghisalba was cofounder and partner of this company, founded early 2018 by experts and commission members of the former CTI (Innosuisse today). The company offers due diligence of companies and projects detailing innovation, potential market risks and benefits with a focus on the life sciences and medtech. The combined experi- ence of the 15 partners range from pharma, medtech, biotech, agrotech, ICT and electronics to banking.

FGen GmbH ( $w w w$.fgen.ch) FGen GmbH is an emerging company that was founded in 2011 as a spin-off from the Department of Biosystems Science and Engineering at the ETH Basel campus. FGen offers biological engineering and high throughput screening services for the development and optimization of microbes and cells. Engineering is done by synthetic biology, directed evolution, and non-GMO approaches while for screening they use a proprietary technology platform. The so-called nanoliter-reactor screening platform applies cell encapsulation and growth in hydrogel beads with volumes in the nanoliter range, which enables the phenotypic analysis of more than 1 million clones per day. As a contract research organization FGen collaborates with partners such as DSM, Evonik, and Ennolys (Lesaffre Group) for the development and improvement of strains for the production of small molecules (vitamins, amino acids, fragrances, chemicals) and proteins (industrial enzymes, food proteins, biologics).

Firmenich (www.firmenich.com) Firmenich was founded in 1895 in Geneva by the Swiss chemist Philippe Chuit and Martin Naef renting the premises of a certain Charles Firmenich. Today, Firmenich is the world's largest privately owned perfume and taste company recording CHF 3.9 billion revenue for the fiscal year 2019. Renowned for its excellent research and creativity, each year, Firmenich invests $10 \%$ of its turnover in R\&D. As a result, Firmenich is a leader in its industry regarding biotechnological manufacturing principles. The company won the prestigious Sepawa Innovation Award for CLEARWOOD ${ }^{\circledR}$, which was launched in 2014. With woody and patchouli notes, it is the first ever perfumery ingredient produced by white biotechnology at large scale. In 2016, Firmenich announced the large-scale production of AMBROX ${ }^{\circledR}$, an amber fragrance with musk and wood tonalities using a fermentation process coupled with proprietary green chemistry resulting in an ingredient with $100 \%$ renewable carbon, followed by the perfumery ingredient Z11 in 2018, which is produced by a similar process.

Givaudan (www.givaudan.com) Givaudan was founded in 1895 , but the history of Givaudan can be traced back to 1796 when Leon Givaudan established a perfumery company in Vernier (Geneva). In 2018 the group generated a turnover of CHF 5.53 billion with 11'725 full time employees worldwide. Like its competitor Firmenich, Givaudan established a strong biotech R\&D to implement biotechnological manufacturing principles. For example, Givaudan filed patents for the application of laccases for fragrance synthesis and developed a biocatalytic process with the French company Proteus for (-)-Ambrox production, using squalene hopene cyclase. ${ }^{[8]}$ Givaudan operates a marine biotechnology centre of excellence in Brittany for the development of novel algae-based cosmetic products. Givaudan strengthened its biotechnology arsenal with a number of acquisitions, such as the French company Soliance, which specializes in microbial and microalgae product sourcing.

Glycemicon (www.glycemicon.com) Glycemicon (glycemic control) is a Swiss start-up and ETH-spin off, based in Brugg, developing novel foods (nutraceuticals) for the maintenance of normal blood sugar using synthetic chemistry for natural products and small molecules. Naturally occurring compounds are identified targeting brown adipose tissue, which is used to dissipate energy in form of heat if needed. The current lead product is a type of naturally occurring bile acid, which can optimize the maintenance of normal blood glucose homeostasis.

GMT Fine Chemicals (www.gmtfinechemicals.ch) GMT is a Swiss company founded in 1998 in the canton Neuchâtel, which focuses on the production of APIs under cGMP, primarily used in oncology and women's health. There are currently 10 employees. GMT has two stainless steel reactors of $3 \mathrm{~m}^{3}$ and $4 \mathrm{~m}^{3}$, a $2.5 \mathrm{~m}^{3}$ glass lined reactor, a horizontal peeler centrifuge and a dryer. 
GMT's products are calcium folinate and calcium Levofolinate. The first FDA inspection was passed successfully in 2017. Cerbios (see above) is the main shareholder of GMT Fine Chemicals.

Helsinn (www.helsinn.com) Helsinn was established in 1976 and is headquartered in Lugano with production facilities in Biasca (TI, Switzerland first established in 1983), Dublin Ireland and subsidiaries in the US, China and Monaco. The family-run company with 700 employees has a cancer care focus. Helsinn is licensing-in and acquiring product rights for development, manufacturing and commercialization from compound originators. The private company then develops and manufactures small molecule APIs including finished dosage forms with a focus on cancer (HPAPIs). Helsinn uses chemical synthesis for the cGMP production of APIs from $\mathrm{kg}$ to tens of tons and for HPAPIs from grams to hundreds of kg. Since 2016, a Helsinn Investment Fonds Luxemburg provides early-stage investment opportunities, with 22 million Euros invested to date including in biotech.

INC Chemie SA (www.inc-chemie.ch) The company produces industrial, cleaning \& care chemicals and specialties since 1981. The product-line covers industrial-chemistry, care-chemistry and specialties, polymer chemistry, colloidal chemistry and chemical processes.

Ineos (www.ineos.com) is a global manufacturer of petrochemicals, specialty chemicals and oil products. Founded in 1998, Ineos grew rapidly through a series of acquisitions, employing 22'000 employees today who formerly used to work for BASF, Bayer, Borealis, BP, Degussa, Dow, Enichem, Hoechst, ICI, Norsk Hydro and Solvay. The company has 183 sites and generates a turnover of $\$ 60$ billion. The company moved their headquarters from London to Lausanne in Switzerland mainly for tax reasons. Ineos Bio is producing cellulosic ethanol in its US biofuel plant near Vero Bach in Florida.

Inofea AG (www.inofea.com) was incorporated in February 2014 in Basel and has developed a new enzyme platform (enzzen ${ }^{\circledR}$-enzymes) to meet a critical industry need: to make enzymes more stable, re-usable and suitable for continuous processes. They immobilize enzymes and protect them with a tailor-made shield, making them easy to use in biocatalysis, bioanalysis, proteomics and as active ingredients. Customers are pharma, food \& feed, specialty chemicals and consumer care companies. Their technology allows the reduction of raw materials needed for synthesis, a reduction of energy consumption during the production process and a reduction of waste and solvents in biocatalytic processes. Based on the enzzen ${ }^{\circledR}$-technology Inofea AG founded Perseo Pharma AG (www.perseo-pharma.com) in 2019 with a focus on therapeutic enzymes for the treatment of cancer and rare genetic diseases.

Lonza (www.lonza.com) Founded in 1897, Lonza is a public company with CHF 5.5 billion (2018) global sales generated with 15'500 employees. Lonza's first product was calcium carbide, which was used to generate acetylene in lamps. Over the years, the product complexity increased with metaldehyde, basic chemicals, agrochemical commodities and vitamin B3. During the late 1960s an Organic Chemical Division including a commercial development function was founded for the synthesis of key building blocks. A biotechnology group was launched in Visp in the early 1980s in response to the increased importance of optically active intermediates and enantiomerically pure drugs. The biotechnology group realized the importance of the biopharmaceutical business, which led to the acquisition in 1996 of Celltech Biologics (UK and US), an early leader in mammalian cell expression and monoclonal antibody production. The acquisition of Cambrex Research Bioproducts und Microbial Biopharmaceuticals followed later. In 2017 Lonza announced the creation of $\mathrm{Ibex}^{\mathrm{TM}}$ Solutions in a new Lonza biopark in Visp with an initial investment of CHF 400 million for biopharmaceuticals production. Today, Lonza is probably the "chemical" company, which successfully offers the broadest combination of biotechnological and chemical technologies for manufacturing purposes.

Mibelle Biochemistry AG (www.mibellebiochemistry.com) Mibelle Biochemistry AG was founded in 1991 as an independent business unit within the Mibelle Group. Mibelle's best-known product is based on apple stem cells using plant cell culture technology (PhytoCellTec ${ }^{\mathrm{TM}}$ ). Other products contain ingredients based on stem cells from alpine rose leaves or stem cells from Burgundy grapes. Single-use $100 \mathrm{~L}$ wave bioreactor technology is used for the production of stem cell biomass which, after passing through a high-pressure homogenizer, is incorporated into lecithin liposomes.

Nestlé (www.nestle.com) The history of the Nestlé Group started with the foundation of the Anglo-Swiss Condensed Milk Company in 1866. Concurrently, Henri Nestlé developed a revolutionary baby formula in 1867 . The company founded by Nestlé merged with the Anglo-Swiss Condensed Milk Company in 1905. Over the last hundred years, Nestlé became the largest Swiss company with group sales of over CHF 91 billion with 308'000 employees. LC1 is a probiotic product of Nestlé containing Lactobacillus johnsonii and is claimed to promote digestive health. Nestlé Health Science invested \$145 million in US-based Aimmune Therapeutics because of Palforzia, a peanut protein formulation with a consistent profile for the desensitization of peanut-allergic patients. Nestlé also recently acquired Allergan's Zenpep, a formulation of pancreas lipase to treat exocrine pancreatic insufficiency. Nestlé Health Science and Codexis formed an innovation partnership for novel enzymes for multiple health conditions.

Omya (www.omya.com) Omya's origins go back to 1884 to a company in Oftringen producing putty with a combination of linseed oil and chalk. Today, Omya is a producer of industrial minerals, mainly fillers and pigments derived from calcium carbonate and dolomite, and a worldwide distributor of specialty chemicals. The company's major markets are forest products (fibre-based products such as paper, board and tissue), polymers, building materials (paints, coatings, sealants, adhesives and construction materials) as well as life sciences (food, feed, pharmaceuticals, cosmetics, environmental products and agriculture). Omya has a global presence extending to more than 180 locations in over 50 countries with 8'000 employees.

PharmaBiome (www.pharmabiome.com) PharmaBiome was founded in 2015 as an ETH Spin-off and is located in Zurich. The company has developed technologies that allow access to an entire range of intestinal bacteria. Anaerobic co-culturing of bacteria is not an easy undertaking, but the required fermentation technologies were developed at the ETH laboratory of Christophe Lacroix. PharmaBiome is using this technology for the development, production and encapsulation of bacterial consortia with the purpose to treat chronic intestinal diseases.

PhytoSwiss Pharma (www.phytoswisspharma.ch) is a small company located in Conthey and founded in 2015. They offer evidence based phytodrugs based on combinations of bioactive botanical drugs with a focus on products preventing and treating diabetes. Artificial intelligence is used to compose synergistic botanical blends for B2B customers.

Polyphor AG (www.polyphor.com) Polyphor was founded in 1996 in Allschwil and currently has about 70 employees. During the IPO in 2018 at the Swiss Stock Exchange Polyphor raised CHF 155 million. Polyphor's focus is the discovery and development of macrocycle antibiotics against Gram-negative microorganisms. Three products are in the clinical development stage. Polyphor focuses on complex macrocycles that can be efficiently synthesized. The MacroFinder library currently consists of >13'000 single purified compounds. The antibiotic Murepavidin (POL7080) is a cyclic synthetic peptidomimetic of natural product like complexity based on the cationic antimicrobial peptide protegrin, which is active against $P$ seudomonas aeruginosa. 
Siegfried (www.siegfried.ch) Founded in 1873, the company generated sales of CHF 794 million in 2018 with about 2'350 employees. The company is publicly listed on the Swiss Stock Exchange in Zurich. Siegfried is an established CMO for chemical synthesis of drug substances, sterile manufacturing and drug products. Siegfried has nine sites - six in Europe, two in the US and one in China. The headquarters are in Zofingen with $543 \mathrm{em}-$ ployees and with a local production capacity of $350 \mathrm{~m}^{3}$. Zofingen and the other sites offer numerous chemical capabilities including the enzyme-catalysed resolution of racemic esters. Siegfried acquired a BASF site in Minden, Germany with 1'458 $\mathrm{m}^{3}$ of production volume, where caffeine, theophylline, ephedrine and pseudoephedrine were produced by Knoll AG, later BASF. This site has decades of experience with yeast-mediated synthesis of e.g. ephedrine.

Sika Group (www.sika.com) was founded in 1910 with a product for the quick waterproofing of the Gotthard tunnel. The company has grown to be a global player with sales of CHF 7.1 bn in 2018 generated with a global workforce of over 20'000. Sika is a member of the SMI (Swiss Market Index) since 2017. Specialty chemicals are at the core of Sika's business today for thermoplastics, adhesive and coating systems. SIKA was a member of a strategic research consortium that looked into the use of laccase enzymes for converting lignin, a waste material from cellulose production, to components of concrete admixtures.

Solvias (www.solvias.com) Solvias was formed in 1999 as a management buy-out of the Scientific Services of Novartis AG. The company is not publicly traded but fully owned by the employees. 521 persons generate a turnover of CHF 93 million. The international expansion was accelerated in 2013 with the acquisition of Confarma. Analytical services, the development of analytic solutions and specialized methods for shorter process validation is the core of Solvias' offering. Biopharmaceutical analysis for the growing biotech companies has become an important contributor to the business. Solvias has also a track record in heterogeneous catalysis, including cGMP custom synthesis and manufacturing of $\mathrm{kg}$ amounts for clinical trials.

SpiroChem AG (www.spirochem.com) is an ETH Zurich spin-off from Erick M. Carreira's lab with headquarters in Basel. With a team of 25, the company offers several services including medicinal chemistry and fee for service contract research, natural product synthesis, analytical services, and consulting.

SSE (www.sse-group.com) The Société Suisse des Éxplosifs SA is a public company founded in 1894 to supply explosives for the tunnel connecting Brig and Domodossola. The production of explosives was the core business until the company decided to diversify in the early 1970s and invested in a new production unit for fine chemicals. In 1983, the SSE Group founded Valsynthèse SA, headquartered in Brig. Valsyntèse SA offers custom pilot and commercial production with hazardous chemical reactions such as nitration and phosgenation $\left(\mathrm{COCl}_{2}\right)$. A new unit was built for the latter in 2014. The SSE group generated sales of CHF 132 million with 650 employees in 2018.

Syngenta (www.syngenta.com) The agro-divisions of Astra Zeneca and Novartis were united in 2000 to form the new global agro player Syngenta. Syngenta was also among the founding members of the Swiss Industrial Biocatalysis Consortium (SIBC) in 2004. In 2016 ChemChina made a successful takeover offer of $\$ 43$ billion to the Syngenta shareholders, and by summer 2017 ChemChina owned $98 \%$ of Syngenta. Syngenta used to be a global player and several sites are still active in Switzerland: Kaisten for the production of a herbicide precursor, Monthey for the production of herbicides, fungicides and insecticides, Münchwilen for the supply of development products for field testing and Stein one of the three global Syngenta R\&D sites. In 2009 Syngenta entered a collaboration with Proteus SA from France for the development of enzymes for next-generation biofuel production. In the last annual report before the ChemChina takeover, Syngenta reported sales of $\$ 12.65$ billion generated with 28'700 employees resulting in an EBITDA of 21\%. In 2020 the agricultural assets of Syngenta, the Dama Group (Israel) and Sinochem were combined into the Syngenta Group with a turnover of USD 23 billion.

SynphaBase (www.synphabase.ch) Established in 2000 in Pratteln, SynphaBase is a spin off at the University of Applied Sciences in Muttenz/Basel. SynphaBase is a custom research and development organization from route finding to process chemistry, offering multi-step synthesis from $\mathrm{mg}$ to metric tons. They work with $\mathrm{CMO}$ (custom manufacturing organization) partners for cGMP commercial batches. The company carries out process development and production of organic and bioactive molecules.

Synple Chem AG (www.synplechem.com) is a start-up founded in 2017. Synple Chem uses disposable reagent cartridges that contain the necessary reagents for an automated capsule-based synthesis, where machines, which are part of the offering, carry out the reactions. The reaction protocol, encoded on a cartridge is loaded onto the machine through a scanner. The approach makes it easier to use equipment for automated, capsule-based synthesis. Currently available reagent cartridges include N-heterocycle formation, reductive amination and PROTAC formation and more cartridges are in development. The technology was invented at the ETH Zurich. It is not clear from their website whether enzymatic reactions can be considered as a future addition.

Tanovis AG (www.tanovis.com) Tanovis is a small company located in central Switzerland in Alpnach. They call themselves the 'lignin company'. They have a proprietary extraction process for the production of pure lignins and derivatives. The process was originally developed to complement cellulose fibre production. Tanovis also promotes brands in the area of food and feed supplements.

Tauderma (www.tauderma.com) Tauderma was founded in 2014 and is located at the Phyto Ark in Monthey. The company uses a proprietary solvent free extraction method to produce Swiss alpine plant extracts for the cosmetic industry. They operate in partnership with Mediplant, also founded in the Valais in 1988.

Vifor Pharma (www.viforpharma.ch) (formerly Galenica Group). The origins of Vifor Pharma go back to Caspar F. Hausmann who specialized in iron products, which he sold in his pharmacy starting in 1872. Intravenous iron products were introduced in the 1950s. Galenica acquired not only Vifor in 1977 but also Laboratories Hausmann AG in 1983, but was finally named Vifor Pharma after the acquisition of Aspreva Pharmaceutical Co in 2008. New iron products are developed with the combined expertise. OM Pharma from Geneva was acquired in 2009, which has small in-house fermentation capacity. Vifor Pharma still specializes in research, development and manufacturing of products to treat iron deficiency for nephrology and cardio-renal therapies. However, CDMO services for the production of intermediates and small molecule APIs are also offered at their sites in Villars-surGlâne and Ettingen. According to the Vifor Pharma 2018 annual report, net sales of CHF 1'585 million and an EBITDA of CHF 391.5 million $(25 \%)$ were achieved with 2'700 employees.

Vio Chemicals (www.viochemicals.com) Established in 2001, Vio Chemicals is a CMO for specialty chemicals, intermediates and APIs produced by chemical synthesis. Vio Chemicals uses cGMP manufacturing facilities in China and India, while their $R \& D$ centre is located in Greece.

While new chemical companies were founded in the last 10 years, others stopped activity after over 100 years in business. In 2019 RohnerChem, a company created in 1906 by Joseph Rohner for the production of formic acid, announced insolvency and is now in liquidation. RohnerChem was a midsize independent CMO for complex fine chemicals and had reactors between 2.5 and $10 \mathrm{~m}^{3}$. The shares were lately held by Arques Industries 
AG, a German investment company. The 200 RohnerChem employees generated sales of about CHF 50 million. RohnerChem and Evocatal (now Evoxx) entered into a strategic cooperation for enzyme-catalysed reactions (ketoreductases, lipases/esterases, transaminases, oxynitrilases, C-C coupling) which now is also history with the dissolution of RohnerChem.

\subsection{Markets and Products}

\subsubsection{General Considerations}

Today, biotechnology and products manufactured using biotechnology affect our daily lives in countless areas. Red and white biotechnology generate annual global sales approaching \$350 billion and continue to grow. ${ }^{[9]}$ Although growth rates for fine chemicals were expected to grow over-proportionally, fine chemicals, intermediates and APIs have not yet achieved their expected potential. However, the basic message remains the same: the economic potential of the white biotechnology sector is theoretically much larger than that in red biotechnology. The chemistry \& pharma sector is an important asset to the Swiss economy. The nominal workplace productivity of the pharmaceutical sector with CHF 351 per unit hours worked is the highest followed by the energy/water supply, finance and chemical industries with CHF 143, CHF 138, and CHF 135, respectively. ${ }^{[10]}$ Organic chemistry and biotechnology are closely related and inter-linked. Long-term thinking for the Swiss economy and especially for the pharma and chemical sectors must be done considering the mutual strengths and limitations. We identified the following boundary conditions to be considered for moving forward in Switzerland.

- A bio-based economy depending exclusively on local resources is not a viable business model, considering limitations in available biomass, except for specific niches which can make sense regionally.

- As a general rule, any life-compatible molecule or product is a candidate for biotechnological production.

- The more bulk character a product has the less attractive it is for a production in Switzerland.

- Due to the complexity of the products of the Swiss pharmaceutical/chemical industry, the E-factor (waste/product) of the sector is very high.

- Synthetic chemistry is still the method of choice even for complex natural molecules.

- Make biocatalysis the initial and not second-generation process in chemo catalysis.

- Dependence of Switzerland from outside manufacturers and the resulting supply insecurity for small molecule prescription drugs.

- High wages and excellent tertiary structure, in combination with no natural resources requires a focus on complex molecules that need novel manufacturing approaches such as synthetic biology and unusual biocatalytic approaches.

- Chemophobia and consumers requiring sustainable and 'natural' or 'organic' products, while some sectors (e.g. flavour and fragrance), which are important for the Swiss economy, are facing uncertain natural raw materials supplies.

- Biotechnology as a tool to increase nominal productivity of the primary sector - where that is possible.

While the 'biologisation' of the pharma sector is a reality today in the red biotechnology sector, it is much less the case in the white biotechnology sector. White biotechnology includes a great number of very diverse organic chemicals for small molecule APIs and intermediates, cosmetics, fragrance and flavours, animal health products, nutrition products, biopolymers, lubricants, and tensioactifs. However, biotechnology is a relatively young discipline and competes with organic synthesis, which originated 200 years ago with the synthesis of urea by Wöhler. Over these 200 years, the organic chemistry toolbox has evolved to the point where the total synthesis of even the most complex secondary metabolite with dozens of chiral centres is now possible. ${ }^{[11]}$ In Switzerland for example, the group of Olivier Baudoin in Basel optimized the total synthesis of (-)-epicoccin $G$ and (-)-rostatin A by breaking $\mathrm{C}-\mathrm{H}$ bonds and simultaneous double ring formation. This results in fewer reduction steps and a considerable increase in total yields. ${ }^{[12]}$ However, even these optimized chemical syntheses are associated with very high production costs and $\mathrm{E}$ factors. In the case of oligopeptides, oligosaccharides, and oligonucleotides these limitations are even greater. In contrast to chemical synthesis, the biosynthesis of natural products is rarely used, which is a paradox considering the biotech options theoretically available.

Another long-term development is the application of artificial intelligence (AI) in chemical synthesis. It appears that $10^{9}$ molecular structures have been created synthetically over the last 100 years, but that the total number of organic molecules is in the order of a mind-boggling $10^{200}$. AI will greatly facilitate the synthesis of new structures, especially for the tedious chemical synthesis of complex natural compounds. Estimations are that AI and learning machines will outperform humans within the next 10-15 years. ${ }^{[13]}$ It can also be anticipated that AI will be an indispensable tool for the in silico design of production organisms. Ideally, AI-based platforms for chemical reactions will be developed with an integrated approach combining both chemical and enzymatic catalysis.

Another issue related to white biotechnology is the number of drug shortages that have increasingly affected physicians and veterinarians in Switzerland and the Western world in general. Many different reasons can trigger a shortage, but one important one is that small molecule API pharmaceutical and veterinarian companies from the Western hemisphere continue to outsource small molecule API production, to companies in China, India and other countries. Producing molecules (primarily small molecule APIs and their intermediates) does not have the same economic status in Switzerland as the steps closer to the patients, such as formulation and clinical application. Mergers and acquisitions further concentrate manufacturing to a very few producers. If manufacturing were to be interrupted or even stopped, there would be a similar effect on the supply of products. The situation is even more aggravated for small-molecule injectables, where quantities cannot be rapidly increased when there is a shortage, due to the more complex infrastructure required.

Finally, companies and producers today are confronted with 'chemophobia', and associations with chemistry today are mostly negative. 'Bio', 'natural' or 'organic' on the other hand have almost only very positive connotations. A study by Rita Saleh et al. from the ETH showed that most lay people were unaware of the similarities between synthetic and natural chemicals. ${ }^{[14]}$ However, the stigmatisation is not observed for pharmaceuticals produced by recombinant technologies or organic chemistry.

\subsubsection{Small Molecule APIs, Intermediates and Fine Chemicals}

The global drug market is expected to break the 1 trillion USD barrier soon. ${ }^{[15]}$ The share of small molecule prescription drugs in percentage continues to decrease relative to biologics. The ratio of small molecule or conventional drugs to biotech products (biopharmaceuticals) sold was $82 \%$ small molecules to $18 \%$ biologics in 2010. In 2019 already biologics products accounted for more than $25 \%$ of all drugs approved between 2015 and 2019 and it is expected that this figure will reach $32 \%$ in 2024. ${ }^{[16]}$ However, considering only the top 100 prescription drugs, the actual ratio of products sold is about one-third biologics versus two-thirds small molecules and it will reach 50:50 in 2024. The market of large therapeutic proteins such as monoclonal antibodies continues to grow but will increasingly have to compete with vaccine therapies, regenerative medicine and gene therapy. 
In other words, the pharmaceutical market will experience great changes in the future. The small molecule pharmaceutical area was an important driver for innovation in biotechnology. With the anticipated shifts and reduced innovation input by the pharmaceutical sector, other industry sectors such as the flavour and fragrance industry for example must take over the lead.

For small molecule APIs, biotechnology mainly has two purposes:

a) synthesis of the drug substance or intermediates;

b) the drug metabolites.

The synthesis of drug metabolites is an important step in drug development. Such metabolites are required for new drug applications for structural elucidation, preparation of analytical reference material, and pharmacological activity testing. Such drug metabolites are byproducts resulting from metabolizing a drug into a different substance in the liver by the specialized enzymes of xenobiotic metabolism. Usually the first step consists of introducing polar groups by the cytochrome $\mathrm{P} 450$ oxidases. Biocatalytic synthesis of metabolites, instead of chemical synthesis, has two advantages: (1) it is more efficient and some metabolites may not be chemically accessible; (2) biocatalytic synthesis is analogous to nature.

The chemo-enzymatic synthesis of small molecule APIs, intermediates and fine chemicals is an established method, ${ }^{[17]}$ in particular to introduce chirality, and the enzymatic toolbox is continuously expanded to meet the ever-increasing degree of sophistication of the molecules required.

One example where organic chemistry reaches its limits is the synthesis of natural products. The tubulin blocker and anticancer drug Eribulin (Halaven ${ }^{\mathrm{TM}}$ ) marketed by Eisai, is a natural chemically produced macrocyclic ketone. Its analogue halichondrin B was originally isolated from the marine sponge Halichondria okadai in 1986. As with many other natural products found in sponges or insects, it can be speculated that this secondary metabolite is originally produced by a bacterium. This is one of many examples of a natural product where synthetic biology must be developed to replace chemical synthesis, with a designer organism assembled for the task. Alternatively, the original (synbiotic) microorganism could be isolated. However, building artificial biological systems, similar to designing an airplane, first in silico, based on a known inventory of standard parts and ultimately then assembled in the laboratory, is still in its infancy. Evolva is presently the only company in Switzerland offering the development of strains for industrial production of higher value small molecules following synthetic biology principles. A comparison of Evolva (www.evolva.com) with a competitor like the US company Gingko Bioworks (www.gingkobioworks.com), reveals some important differences, although both have a very similar B2B (business to business) business model. Gingko Bioworks was cited as the most valuable venture-backed company in Boston. Evolva's market capitalization was about CHF 170 million but the share price continuously dropped from about CHF 30 to cents. While Gingko Bioworks keeps hiring, Evolva has been reducing its staff. Key products of Evolva are stevia, plus nootkatone and resveratrol. Unlike Gingko Bioworks, Evolva does not seem to cooperate with companies for the production of small molecule pharmaceuticals. Comparing their science and technological approach Evolva uses yeast, whereas Gingko calls itself "the organism company", and also uses yeast but is open to use other organisms. Moreover, Gingko stresses its integrated software, automation tools for rapid strain engineering, high throughput DNA (sequencing, synthesis, cloning) based on a code base of cells, enzymes and genetic programs.

\subsubsection{Peptides}

Since the launch of recombinant insulin and the commercial approval of recombinant monoclonal antibodies, the recombinant therapeutic protein market had an annual growth of 15-19\%.
Nevertheless, large-scale manufacturing of peptides, in particular of long-chain peptides, in amounts greater than $100 \mathrm{~kg}$ remains very challenging and requires a lot of tedious development work. ${ }^{[18]}$ In the pharma sector, for which most of the commercial peptides are produced today, the products with the largest volumes, such as the insulins or the peptide-backbone of liraglutide, are produced recombinantly, while peptides required in smaller volumes or chemically modified peptides are generally produced via chemical synthesis. ${ }^{[19]}$

Living matter produces peptides either ribosomally or non-ribosomally. Ribosomal synthesis translates the information of the DNA via ribosomal RNA into a mostly linear protein or peptide. A set of twenty canonical or coded (natural) amino acids are used for ribosomal peptide synthesis. In some cases, ribosomal proteins are post-translationally modified by glycosylation, phosphorylation, hydroxylation, sulfonation, palmitylation, disulfide-bridge formation or by other intra- or inter-molecular reactions.

The system of non-ribosomal peptide synthetases uses synthesis schemes involved in the formation of fatty acids and polyketides, and often leads to peptides containing linkages other than peptide-bonds. A cascade of enzymatic reactions, resulting in linear or cyclic products, synthesizes the non-ribosomal peptides. Because of the enzymatic nature of this synthetic route, chemical manipulations are possible.

Both natural pathways to peptides can in principle be used for manufacturing as alternatives to chemical solid-phase or liquid-phase synthesis. However, two major structural limitations, which are valid for all recombinant approaches, should be mentioned: (1) Only peptides containing canonical amino acids can be industrially manufactured efficiently by fermentation with recombinant microorganisms; (2) peptides with an amide function at the C-terminus, as required by many APIs, cannot be obtained directly by recombinant synthesis. This requires either adding an additional C-terminal glycine, which is then transformed enzymatically into an amide function or performing a chemical modification, which is difficult, as it can lead to the racemization of the C-teminal amino acid.

An additional problem encountered in recombinant peptide synthesis results from the relatively small size and the lack of tertiary structure of these products, which, when remaining dissolved in the cytoplasm, are rapidly digested by the numerous proteases present inside the cells. In order to avoid this degradation issue, the following concepts have been developed:

a) synthesis of the peptide as part of a fusion protein;

b) synthesis of larger multicopy constructs (concatemers);

c) use of a host that can secrete the peptide into the growth medium.

The concatemer approach is certainly more elegant than the fusion protein concept, as most of the overexpressed product corresponds to the desired product. However, the concatemer approach requires at least one enzyme to cut the concatemer and sometimes another enzyme for trimming the C-terminus to obtain the desired product. For the secretion strategy, it is important to mention, that some of the well-known secreting microorganisms such as Bacillus or yeast, e.g. Pichia sp., are known to also secrete proteases into the fermentation medium, which can be an issue for product stability.

Two interesting technologies for recombinant peptide synthesis have recently been developed by the German start-up company Numaferm using variants of the fusion protein concept.[20] The first approach takes advantage of fusion with a protein called NUMAtag (a fragment of hemolysin C or hemolysin A), which allows secreting the fusion protein using the Type 1 secretion system of Escherichia coli into the protease-free supernatant. ${ }^{[21]}$ The second concept is called NUMAswitch, where the fusion proteins are expressed as inclusion bodies. Interestingly, it uses the same fusion tags, but under different expression and cultivation conditions. ${ }^{[22]}$ 
The German start-up company MK2 Biotechnologies has recently developed another promising fusion protein technology. The fusion protein consists of three components: (1) a purification domain, which is designed to bind to a polysaccharide, e.g. cellulose or starch; (2) a viral auto-protease domain; (3) the target peptide/protein. The autoprotease cleaves the fusion protein between the $\mathrm{C}$-terminus of the auto-protease domain and $\mathrm{N}$-terminus of the target peptide/protein. ${ }^{[23]}$

\subsubsection{Oligonucleotides}

One of the biggest challenges over the next decades will be food security, driven by a growing world population, which is forecast to reach 9.7 billion people by 2050 .

Pests cause significant losses every year that are estimated to be in the range of USD 100 billion. ${ }^{[24]}$ The ban of neonicotinoids in a number of countries and the recent public discussions around glyphosate means that there is a desperate need for better, more sustainable and environmentally friendly pesticides.

dsRNA-based pesticides for the selective silencing of the essential genes of targeted pathogens, such as plant viruses, fungi or insects ${ }^{[25]}$ are a promising concept. CSIRO in Australia pioneered the use of RNA interference in the late 1990s as a high-precision tool for exploring and manipulating gene functions in plants. ${ }^{[26}$ Since then, the mechanism of gene silencing in plants using long dsRNA has been validated in a number of commercial examples in which the dsRNA is produced endogenously inside the corresponding GMO plant and is directed to silence the translation of relevant genes. Prominent examples of this technology are the blue rose developed by Florigene and Suntory, the not-browning apples developed by Okanagan Specialty Fruits or the FlavrSavr tomato developed by Calgene, virus-resistant papaya, squash, plums, potatoes and beans or bruise-resistant potatoes. An example of a GMO plant using endogenously expressed dsRNA for silencing a target outside a plant is MON 87411, a maize which expresses DvSnf7 RNA to protect against corn rootworm (Diabrotica spp.). It is important to note that none of these GMO products are authorized in Switzerland and the EU.

Synthetic dsRNA can also be applied by spraying. Bioinformatics allows the design of dsRNA molecules that are highly specific for the targeted pests and are essentially free of undesired side effects on other organisms. In addition, dsRNAs are known to be rapidly degraded into natural and non-toxic metabolites in the environment. ${ }^{[27]}$ Nevertheless, the regulatory approval of this type of product will be a demanding and complex process, and two technical objectives will have to be successfully achieved:

a) The development of industrial manufacturing processes able

to supply the corresponding dsRNA products in the required amounts and at affordable costs;

b) The development of suitable formulation and delivery solutions, providing sufficient stability to the dsRNAs without negatively affecting the delivery.

Sometimes the dsRNA needs to be over 900 base pairs in length to achieve efficient silencing. ${ }^{[28]}$ From a manufacturing perspective, producing the required amounts of such dsRNAs represents a manufacturing challenge. Even with high efficiency and assuming a low dose requirement of dsRNA pesticides the corresponding commercial quantities will be very high.

Today, dsRNA molecules are synthesized using expression systems either in vivo or in vitro. The majority of the expression systems in vivo are based on the fermentation of genetically modified $E$. coli strains that are RNAse III-deficient and constitutively express a T7 DNA-dependent-RNA-polymerase. ${ }^{[29]}$ Other microbial systems which are used for the expression of long dsRNA in vivo include Pseudomonas syringae, ${ }^{[30]}$ Clostridium glutamicum $^{[31]}$ and others. The US start-up company RNAgri (former name APSE Technology), which is seeking to produce low cost
dsRNA, described the beneficial effect of the co-expression of viral capsid proteins on the yields of dsRNA produced by microbial fermentation. ${ }^{[32]}$

Several concepts for transcription of dsRNA in vitro are presented in the literature. While these laboratory methods are sufficient to cover $R \& D$ requirements, they are not scalable to ensure the supply for commercial applications. To overcome this issue, the US start-up company GreenLight Biosciences has developed a cell-free production platform. ${ }^{[33]}$ This system requires a range of components that are produced in two separate microbial fermentations, followed by a chemo-enzymatic and a transcription step in vitro. This technology was scaled-up to produce sufficient amounts to perform a range of field trials against Colorado potato beetle. ${ }^{[34]}$

The formulation of dsRNA pesticides should stabilize the dsRNA molecules under environmental conditions over a sufficient period and should allow the uptake of sufficient amounts of the dsRNA by the targeted plants to achieve the desired silencing effect.

A group of scientists in Australia has developed an interesting formulation solution, using synthetic clay inorganic nanosheets (BioClay). Once loaded on the clay, the dsRNA does not wash off the leaves, shows a sustained release, and an increased silencing efficiency when compared to a naked dsRNA.[35]

The US start-up company Agrospheres has developed another interesting formulation for dsRNAs, which takes advantage of so-called bacterial minicells as delivery vehicles, which can be produced by overexpressing the tubulin-homolog FtsZ in E. coli. They are unable to replicate, cause infection or ecological harm, but they can continue other cellular processes, such as ATP synthesis, replication and transcription of plasmid DNA, and translation of mRNA. dsRNA can be loaded into the minicells by mixing them in solution. The dsRNA can also be produced directly inside the minicells during fermentation. ${ }^{[36]}$

\subsubsection{Protein-based Biopolymers}

Structural proteins are a ubiquitous class of biopolymers. In nature, many proteins assemble into functional structures with unique physical and mechanical properties that are not found in conventional synthetic polymers. In particular, natural structural proteins have unique combinations of high elasticity, toughness, and mechanical strength. Proteins are also fully biodegradable in the environment and most of them are highly biocompatible. This would make structural proteins a material of choice for many applications in biomedicine and consumer goods.

To make use of this potential, numerous scientific groups in both academia ${ }^{[37]}$ and industry ${ }^{[38]}$ have invested considerable efforts into the manufacturing and processing of such structural proteins.

Two main classes of structural proteins were investigated: recombinant spider silks and recombinant human collagens. However, it soon became clear that the industrial production of these materials was not possible with the biotechnology toolbox available at that time. For spider silks, the problems were twofold. First the repetitive nature of the spider silk genes made the molecular biology work very difficult. Secondly, the large size of the native spider silk proteins, which can be $250-320 \mathrm{kDa}$, is beyond what can easily be produced in established microbial expression systems.

During the first decade of the new century, a number of startup companies have entered into the race to develop and industrialise protein-based biopolymers, and now, another 12-15 years later, it appears that the first large-scale products may finally reach the market.

The German start-up company AMSilk has been investigating biopolymers based on bioengineered spider silk proteins for a wide range of applications since 2008. AMSilk's Biosteel ${ }^{\mathrm{TM}}$ fibre 
is currently under development for high-tech material applications with Airbus and Adidas. AMSilk claim to have scaled-up the fermentation process to above 50'000 L, and to have also mastered the fibre-spinning process. Another application of AMSilk proteins is as a coating for breast implants. AMSilk also developed their proteins as cosmetic ingredients; this business was recently sold to Givaudan.

Another bioengineered spider silk protein, Brewed Protein ${ }^{\mathrm{TM}}$, was developed by Spiber Inc., which was founded in 2007 in Japan. Spiber is currently building a dedicated green-field fermentation facility in Thailand, to ensure the commercial supply of Brewed Protein $^{\mathrm{TM}}$. The production of the textile fibres will remain in Japan. Spiber has an ongoing collaboration with North Face, which led to the production of prototypes of a sports-jacket called the Moon Parka. Another industrial collaboration of Spiber is with Kojima Industries, who are developing automotive parts for Toyota.

The US start-up company Bolt Threads, is another player in recombinant bioengineered spider silk proteins. Bolt Threads, which was founded as Refractored Materials in 2009, has raised over $\$ 210$ million, at a remarkable valuation of $\$ 700$ million in the latest financing round. Bolt Threads produce their proteins in a yeast secretion process, and is also targeting the textile and personal care markets. For their fibre protein Microsilk ${ }^{\mathrm{TM}}$, they have reported collaborations in the field of textiles with Patagonia as well as with Stella McCartney and Adidas. Bolt Threads have also created their own line of cosmetic products based on the so-called B-Silk ${ }^{\mathrm{TM}}$ protein.

The US startup Kraig Biocraft Laboratories (KBL) has a different approach towards producing bioengineered spider silk proteins. KBL developed several genetically modified silkworm lines. ${ }^{[39]}$ Two of the strains produce the genetically engineered silk variants called Dragon Silk ${ }^{\mathrm{TM}}$ and Monster Silk ${ }^{\mathrm{TM}}$, both variants contain spider silk motifs and show enhanced mechanical properties. KBL is currently scaling-up the industrial manufacturing of these silks at Prodigy Textiles, the Company's Vietnamese subsidiary. KBL's primary target is protective materials for the US army. KBL is listed on the US OTC market and has currently a market capitalization of over \$100 million.

Collagens are structural proteins in the extracellular matrix and in connective tissues. They are the most abundant class of proteins in humans and animals. Collagen-based medicinal products are widely used in different regenerative medicine applications. Despite significant efforts into the development of commercially viable recombinant processes for the production of human collagen (e.g. Fuji, Fibrogen), collagen is still mostly isolated from animal sources (mostly bovine, porcine or rat tail). The reason for this lies in the difficulties associated with the efficient expression of full-size human collagens in microbial systems and the post-translational modifications required for a functional material. For human collagen, the modification of certain Pro residues to hydroxyl-Pro is needed and this requires the co-expression of the enzyme prolyl 4-hydroxylase (P4H). In order to overcome these issues, the Israel-based start-up company CollPlant has developed an interesting process for the production of recombinant Human type I Collagen (rhCollagen ${ }^{\mathrm{TM}}$ ) in transgenic Tobacco Plants. The company, which has been listed on the NASDAQ since 2018, intends to develop the product for the 3D bioprinting, aesthetic, and advanced wound care markets.

While natural scientists are continuing to discover additional natural proteins with extraordinary properties, ${ }^{[40]}$ it becomes evident that designed synthetic proteins are getting more and more attention and will ultimately play a decisive role for the development of future commercial products. ${ }^{[41]}$

\subsubsection{Flavour, Fragrance and Cosmetics}

Two Swiss companies located in Geneva, Givaudan and Firmenich, account for about one third of the global sales of flavours and fragrances. Today's customers want 'organic' and 'natural' flavour, fragrance, cosmetics, and health care products in general, and require that products to be manufactured sustainably. This trend is nurtured by an unspecified fear of chemical substances or chemophobia by laypeople for which the term 'chemical substances' has a negative connotation. ${ }^{[42]}$ Moreover, the cost of plant-based raw materials is increasing, while supply is becoming irregular because of overharvesting and natural variations of crop quality and quantity. Organic synthesis is not really an alternative because these products cannot be labelled as 'natural' or 'bio'. Thus, flavours and fragrances are an example of how producers can profit by switching their manufacturing basis from extraction and chemical synthesis to fermentation and biocatalysis. As a result, the new trend in this industry, which uses over 9000 synthetic and natural ingredients, is to switch to biotechnology to meet the expectations of consumers. Firmenich has developed a process for a 'green note' fragrance produced with a four-step biocatalysis procedure. Cell factories can produce by biosynthesis terpenes, which have a huge structural diversity (e.g. santalol, nootkatone, patchulol, ambrox, menthol). One of the most important botanical extracts is patchouli oil, which is obtained by steam distillation of plant leaves. Clearwood ${ }^{\circledR}$, which has a similar but not identical fragrance and chemical composition is now produced with a recombinant microbial strain. ${ }^{[43]}$ Plant cell culture was not as productive. Another example is Ambrox. Ambergris is an excretion of the sperm whale Physter macrocephalus. It ages under the action of seawater and air and develops a pleasant odour, due to the oxidative degradation of (-)-Ambrein, an otherwise odourless compound, to Ambrox. Ambrox is the olfactorily most important compound of ambergris and this expensive and valuable perfumery ingredient is produced biocatalytically by Givaudan as Ambrofix ${ }^{\circledR[44]}$ using squalene hopene cyclase from Alicyclobacillus acidocaldarius that is cloned into an $E$. coli host.

Because of supply issues, diversity and complexity of the products, consumer attitude, and the high margins of the products, we anticipate that the flavour \& fragrance industry will drive innovation in white biotechnology in Switzerland, filling the gap left by the small molecule pharmaceutical industry.

\subsubsection{Food \& Feed, Dietary Supplements}

Probably one third of our daily food is processed by fermentation in one way or another. The food and beverage industry were early adopters of biotech methods, using fermentation, biocatalysis or biotransformation for new products and better manufacturing processes. Enzymes have become indispensable processing tools in the baking industry, in wine, brewing, and cheese manufacturing. The global feed enzyme market of USD 1.2 billion is also growing and important for pig and poultry nutrition. ${ }^{[45]}$ Half of the marketed pure vitamins are produced using fermentation or with a hybrid biotech-chemical process. Asparaginases are used to reduce traces of acrylamide produced during the industrial processing of food products. Sucralose or Splenda ${ }^{\circledR}$ discovered in 1976 by Tate $\&$ Lyle is produced by a chemo-enzymatic process. Most PUFAs are not extracted from fish liver anymore but produced by fermentation. The coenzyme Q10 (also called ubiquinone), which was originally extracted from bovine hearts, was more expensive than gold until a fermentation process with yeast replaced the extraction process. The human gut microbiome consists of up to 1000 different microbial species. But less than 100 species are believed to play a major role. However, the balance between them has a major impact upon health, where HMOs (Human Milk Oligosaccharides) play a crucial role. The most abundant HMO is 2'-fucosyllactose. A human identical product, manufactured by fermentation, has been approved in the US and Europe as an ingredient for infant formula and functional nutrition. Aspartame or Nutrasweet ${ }^{\circledR} /$ Equal $^{\circledR}$ is produced by a chemo-enzymatic process 
in a collaboration between DSM and TOSOH. Stevia or rebaudioside $\mathrm{M}$ is manufactured for PEPSI using a chemo-enzymatic (recombinant glycosidase) process. EverSweet ${ }^{\mathrm{TM}}$ Stevia is also one of Evolva's brand products produced by Cargill in the US. There must be well over fifty companies worldwide looking for alternatives to unsustainable meat and fish production. For example, Mosa Meat, NL and Aleph Farms Israel cultivate bovine cells and Blue Nalu, USA cultivates fish cells in suspension culture. Impossible Foods, USA have a patent for a recombinant Pichia pastoris heme protein for 'artificial' meat. There are also Swiss companies producing meat substitutes (e.g. Planted) but they are all based on plant raw materials. All these examples show that the food, feed, and dietary supplement sector must be another target for biotech innovation in Switzerland and a key contributor to the Swiss economy.

\subsubsection{Commodities and Biofuels}

Commodity chemicals or biofuels that can be produced by biotechnology are typically products of the primary metabolism. The required up-stream fermentation and downstream processing technology for isolation and purification are not technical hurdles. However, availability and reliable deployment of the required biomass feedstock are the decisive factors. The raw materials can either be produced locally by agriculture and silviculture or imported. In Switzerland, the importation of 'biomass' in the form of sugar cane molasses for fermentation has been practiced for decades. However, importing unprocessed biomass such as wood or straw for fermentative production of commodities does certainly not make sense for economic reasons.

Sugar production in Switzerland always needed economic protection measures, particularly since the liberalisation of the sugar market by the European Union in 2017. As of 2019, extra customs duties of CHF 70 per imported ton were imposed and the contribution of CHF 300 per hectare paid to sugar farmers was increased by CHF 300 to CHF 2'100. These protective measures are increasingly criticised as they are counterproductive and not sustainable.

The Eidgenössische Forschungsanstalt für Wald, Schnee und Landschaft WSL estimated the biomass potential in Switzerland for energy-related use. ${ }^{[46]}$ The study shows that in addition to the biomass already used the additional potential of all the lignified and non-lignified biomass, including manure and other organic waste, could provide only an additional $4 \%$ of the country's gross energy requirements, let alone be used as raw materials for chemical commodity production. Thus, the bio-based production of commodity chemicals such as acetic acid, succinic acid or others does not make sense in Switzerland, but the development of innovative processes, which can be licensed out, may. The 'biologisation' of the energy sector is difficult due to the low yield of photosynthesis and the comparative low energy content of the biomaterial. Except for the local use of wood for heating or the generation of methane with bio-waste, biotechnology is not a solution. The same holds true for the local production of bio-based bulk chemicals at present costs and prices levels.

One of the questions asked earlier was whether biotechnology can be used to increase the nominal productivity of the primary sector, which is about ten times lower than that in the chemical/ pharmaceutical sector. Here the moratorium on GMOs, introduced in 2005, is a major roadblock. This moratorium prohibits the use of genetically modified plants in agriculture, silviculture or horticulture and is valid until 2021. With the new parliament elected in 2019, this moratorium will most like remain in place. Permission to make use of modern genetic tools is a requirement for any biotechnology-based approach to improving the economy in the sectors under discussion, as they allow a tailored design of crop plants so that all parts can be used optimally. With respect to GMO regulations, we also recommend that CRISPR-Cas9 should be legislated as 'genome editing' instead of 'genetically modified', as this comparatively cheap and precise genetic tool would allow smaller seed producers to compete against the large global players.

Another fact to consider is that the arable land available in Switzerland can only feed half of its fast-growing population. Securing the supply of food in times of shrinking arable land resources and climate change will only be possible with technological options. Again, this leaves no room for cheap bio-based commodities in Switzerland.

\section{Research and Academia}

Research efforts over the last decades have established biocatalysis and biosynthesis, that is the application of enzymes and microbes in synthetic chemistry, as a practical and environmentally friendly complement to organic chemistry. ${ }^{[4]}$ Enzymes have been tailored to carry out chiral resolutions ${ }^{[48,49]}$ for the manufacture of chiral alcohols ${ }^{[50]}$ and amines ${ }^{[52,53]}$ and in this way are "Bringing New Chemistry to Life" as the 2018 Nobel laureate in chemistry Frances Arnold so aptly describes it. ${ }^{[53]}$ Globally, several small molecule pharmaceuticals that use biocatalysis in their synthesis are among the pharma industry's elite group of blockbuster drugs whereas biosynthetic approaches are harnessed to produce fine chemicals such as fragrances, flavours and nutraceuticals, and bulk chemicals from sustainable feedstocks. ${ }^{[54]}$

Going beyond the established enzyme families such as hydrolases and ketoreductases, intriguing chemistries such as biocatalytic imine reductions ${ }^{[55]}$ have recently been described for the $\mathrm{kg}$ production of a key intermediate to GSK2879552, a lysine-specific demethylase-1 inhibitor. ${ }^{[56]}$ Moreover, the establishment of (chemo)-enzymatic cascades ${ }^{[57]}$ shows great promise for streamlining synthetic routes to valuable products such as the investigational HIV drug islatravir. ${ }^{[58]}$

Switzerland's academic white biotechnology community is actively contributing to the increasing success of applied biocatalysis and biosynthesis. By giving the most recent successful examples of selected areas of white biotechnology, the aim of this chapter is to highlight main research directions and to give an overview of the expertise of the academic biocatalysis community in Switzerland.

\subsection{Novel Chemistries}

Improving the technological readiness of additional enzyme families allows the chemical community to tap into novel reactivities and to expand the palette of accessible molecules. Possible sources of novel chemistries are, for example, the creation of enzymes via computational de novo design, ${ }^{[59]}$ repurposing existing proteins through exploitation of metal cofactors ${ }^{[60]}$ and the utilization of as yet under-explored enzyme classes. ${ }^{[61]}$

By combining computational design and laboratory evolution, Donald Hilvert and coworkers (ETH Zurich) transformed a naïve zinc-binding peptide into a globular enzyme capable of catalysing ester cleavage with exacting enantiospecificity and high catalytic efficiency $\left(k_{\text {cat }} / K_{\mathrm{M}} \sim 10^{6} \mathrm{M}^{-1} \mathrm{~s}^{-1}\right)$. The successful optimisation of both structure and function might indicate that the putative evolutionary trajectories of ancestral proteins might be adaptable for the development of new (metal-dependent) enzymes. In addition, the researchers concluded that promiscuous binding of different substrate molecules and metal ions by primordial scaffolds might have been a rich source of novel activities. [62]

Artificial metalloenzymes, which combine the versatile reaction scope of transition metals with the beneficial catalytic features of enzymes are another source of novel catalysts for abiotic reactions. Focusing on an established protein system in which an abiotic cofactor had been incorporated (biotin-streptavidin technology for the generation of artificial metalloenzymes), [63] Thomas Ward (University of Basel), Sven Panke (ETH Zurich) 
and coworkers targeted the optimization of the biocatalyst for in vivo metathesis by directed evolution. By compartmentalizing the artificial metallohydrolase in the periplasm of E. coli, a functional 'metathase' could be assembled in vivo and - exploiting the higher screening throughput the new setup allowed - was further optimized by rational design and iterative site mutagenesis. After evaluation of more than 3000 clones, this directed evolution protocol led to the identification of a quintuple mutant ( $\left.\mathrm{SAV}^{\mathrm{mut}}\right)$ which in complex with a biotinylated Hoveyda-Grubbs second-generation catalyst (biot-Ru) displayed a cell-specific activity $5.4 \pm 1.2$ (mean \pm s.d.) times higher than that of the original biot-Ru saturated protein variant. ${ }^{[64]}$

Interesting chemistries can also be accessed through the use and optimization of natural enzymes. In their quest to realize the potential of $S$-adenosylmethionine-dependent (SAM-dependent) methyltransferases for the regio-, chemo- and stereospecific methylation of complex natural or synthetic compounds, Florian Seebeck and coworkers (University of Basel) coupled $C$-, $N$ - and $O$-specific methyltransferases (MTs) with halide methyl transferases (HMTs) in an enzymatic cascade. In this way, the authors engineered efficient reaction cascades that afforded preparative and nearly quantitative methylation of molecules such as histidine, inositol, diamine putrescine, alpha-ketovaleric acid and 2,7-dihydroxynaphthalene using the off-the-shelf reagent methyl iodide to fuel the reaction while reducing the level of SAM to catalytic concentrations. ${ }^{[65]}$ These results may form the base for examining the applicability of the HMT/MT cascade to large-scale reactions making them accessible for the functionalization of a wide range of complex molecules.

Similarly, Rebecca Buller and coworkers (Zurich University of Applied Sciences) explored the selective biocatalytic halogenation of unactivated $\mathrm{C}\left(\mathrm{sp}^{3}\right)-\mathrm{H}$ bonds to change the properties of pharmaceuticals and agrochemicals or to install chemical handles for further functionalization. By using structure-guided evolution of the non-heme iron halogenase WelO5*, the authors designed an enzyme exhibiting a more than 290-fold higher turnover number and a 400 -fold higher apparent $k_{\text {cat }}$ compared to the wild type for the selective chlorination of a martinelline-derived fragment. [66] This first example of enzyme engineering of a non-heme iron halogenase highlights the ease with which the substrate scope of this enzyme family can be expanded beyond the native indole alkaloid-type substrates, opening the door for further applications.

\subsection{Reduced Reliance on Fossil Energy}

Concerns about climate change in combination with the global cost volatility of fossil energy have become a global driving force to reduce reliance on fossil oil and use biomass as a resource for bio-based manufacturing. The promotion of a bio-based economy, however, can only be achieved by the development of a comprehensive toolbox that may be used to convert available biomass into a multitude of required products.

Lignin, which is a major component of lignocellulosic biomass, is the largest source of aromatic functionalities and as such could serve as a feedstock for the production of renewable chemicals or fuels. To access lignin as a feedstock practical, high-yield lignin depolymerization methods are required as the use of acid and high temperatures during lignin extraction triggers strong and irreversible condensation of the material, which negatively affects upgrading. By adding formaldehyde during biomass pretreatment, Jeremy Luterbacher and coworkers (EPF Lausanne) showed that a soluble lignin fraction was obtained in the process resulting into near theoretical yields of the syringyl and guaiacyl monomers in the subsequent hydrogenolysis reaction. The yields observed by the researchers in Lausanne were three to seven times higher than those obtained without formaldehyde, suggesting that lignin-upgrading could be integrated into current biorefinery schemes to optimise productivity and profitability. ${ }^{[67]}$
Another approach to transform renewable resources into value-added products comprises the integration of powerful enzyme cascades with man-made catalysts. However, the often-occurring mutual incompatibility of bio- and chemocatalysts challenges the set-up of chemo-enzymatic cascades. Elegantly addressing this challenge, Tom Ward and coworkers (University of Basel) designed a chemo-enzymatic approach to produce cycloalkenes from bio-based resources by compartmentalising a complex enzyme cascade into $E$. coli enabling the simultaneous use of a metathesis catalysts in an aqueous-m-dodecane two phase system. Using this strategy, cyclopentene, cyclohexene and cycloheptene could be produced from olive oil and its derivatives via an enzymatic cascade consisting of up to nine steps followed by ring closing metathesis. ${ }^{[68]}$

In light of the current plastic crisis, the biodegradable polyhydroxyalkanoates (PHAs) have gained considerable importance due to their structural diversity and similarity to conventional synthetic plastics. Focusing biosynthetic production Manfred Zinn and coworkers (University of Applied Sciences and Arts Western Switzerland) have recently looked into the influence of unusual co-substrates on the biosynthesis of medium-chain-length PHA produced in multistage chemostat reactors. Producing tailor-made, functionalized PHAs in a twostage approach, in which biomass production was separated from PHA synthesis, the influence of unusual precursors such a 10 -undecenoic acid or phenylvaleric acid on polymer molecular weight was explored. ${ }^{69]}$

\subsection{Enabling Technologies for Enzyme Engineering and Biocatalysis}

Whenever time is the determining factor in the development race between chemistry and white biotechnology, the latter is often at a disadvantage as synthetic organic chemistry is still dominant in almost all chemical companies. ${ }^{[70]}$ Methods and technologies to increase enzyme compatibility and robustness or which accelerate the biocatalysis process development time are consequently in great demand as they directly increase the impact of biocatalysis on many potential industrial processes.

Engineering enzymes for practical applications often crucially depends on the screening of large enzyme variant libraries, making the process of directed evolution laborious and time-consuming. Available high-throughput methods, however, mostly depend on the use of labelled substrates and are, therefore, often unsuitable for many real-world applications. To test high-throughput techniques, Donald Hilvert and coworkers (ETH Zurich) set out to implement an ultra-high throughput microfluidic assay for the optimization of oxidases. By introducing a label-free assay relying on the detection of hydrogen peroxide production, the researchers improved a cyclohexylamine oxidase by a factor of 960 for the racemic resolution of 1-phenyl-1,2,3,4-tetrahydroisoquinoline, whose $(S)$-enantiomer is a key precursor of the blockbuster drug solifenacin, in a single evolutionary round. ${ }^{[71]}$ The researchers also showed that fluorescent activated droplet sorting (FADS) is a powerful technology enabling biocatalyst engineering within a timeframe suitable for today's condensed process development.

Even with a highly active enzyme variant in hand, denaturing stresses such as high substrate loads, organic solvents, and elevated temperatures can limit the biocatalyst's applicability, as many synthetically interesting enzymes are sensitive to these factors. Targeting to improve enzyme robustness, Patrick Shahgaldian and coworkers (University of Applied Sciences and Arts Northwestern Switzerland) used a synthetic chemical strategy to produce hybrid organic/inorganic nanobiocatalysts shielded by a soft organosilica layer. Within their shell, a set of different biocatalysts exhibited increased tolerance to temperature and $\mathrm{pH}$ as well as to ultrasound, urea, SDS and protease treatment. ${ }^{[72]}$ 
Going one step further in the process development chain, Francesca Paradisi and coworkers (University of Bern) established a self-sustaining closed-loop multi-enzyme platform for the biocatalytic synthesis of a large range of non-commercially available products in a continuous flow. Targeting the production of alcohols from amine starting materials, the researchers used immobilized transaminase and redox enzymes to obtain a range of primary and secondary alcohols by mimicking cellular enzyme cascades in a continuous-flow bioreactor. Yields (80 to >99\%) and optical purity of secondary alcohols ( $>99$ enantiomeric excess) were very good and the manufactured products included high-value alcohols such as hydroxytyrosol and enantiopure 2-arylpropanols. ${ }^{[73]}$

In light of these exciting successes, the further strengthening of Switzerland's position in the white biotechnology sector and its differentiation from low-cost producing countries is crucially important. One key element to reach this goal will be to foster the close dialog between academia and industry. The network program 'Innovation in Biocatalysis', which is part of the project-based contributions 2017-2020 and managed by the Competence Center of Biocatalysis (CCBIO) at the Zurich University of Applied Sciences, facilitates such interactions and shapes a dynamic biocatalysis community.

\section{Outlook and Proposal on how to Proceed}

One can conclude that in a number of fields there will be an increasing demand and potential for white biotechnology products. Which products and markets to address need to be identified, because the baseline for white biotechnology in Switzerland is a different one when compared to other European countries, due to the actual industrial basis and the attributes of its primary sector. There are an estimated thousand small companies in Switzerland that will potentially be affected by disruptive forces and developments that will affect the way we use and produce chemicals. There is no overall strategy for the future development of white biotechnology in Switzerland. How can we repeat the innovation in the Swiss red biotechnology sector? There have been isolated attempts in the past. Now is the time to coordinate efforts to set priorities in R\&D that will be relevant for the Swiss economy. We need novel technologies and synthetic methods but we also need approaches in the way we collaborate and interact.

The first step will be to bring the following associations and organizations around a table to agree on a common denominator and to formulate a detailed action plan.

- BioAlps Life sciences cluster of western Switzerland

- CCBIO Competence Center for Biocatalysis

- SATW Swiss Academy of Engineering Sciences (working group biotechnology)

- SBA Swiss Biotech Association

- SCCER CREST Competence Center for Research in Energy, Society and Transition

- scienceindustries

- SIBC Swiss Industrial Biocatalysis Consortium

- SKB Swiss Coordination Committee Biotechnology The existing SBA platform should not restrict itself to red biotechnology, it should also be used for white biotechnology. The SBA and SATW agreed that the SATW working group biotechnology should outline a working program with the above organizations and selected stakeholders, which will define the basis in a series of working sessions. In the long term, the SBA will also lead coordination of the white biotechnology sector in Switzerland. Its findings will be on its interactive website.

The working agenda is as follows:

- A directory of white biotech stakeholders, production capabilities and innovation needs.

- Rethink the way we cooperate and try radically new ways of interactions (e.g. blockchain for open innovation).
- Establish the SBA platform as the information broker for white biotech in Switzerland.

- Consider the consequences of AI (artificial intelligence) for chemo enzymatic synthetic purposes.

- Strengthen the synthetic biotechnological cooperation within Switzerland.

- Identify additional promising fields of future disruptive development, e.g. next-generation protein-based 'designer' polymers.

From a technological perspective, there are several options and tools available, including combinations thereof, which can be used for the production of organic molecules: biocatalysis (free or immobilized enzymes), biotransformation (whole cells, dead or alive) and biosynthesis (de novo synthesis by fermentation). Biocatalysis and biotransformation will remain important niche technologies, complementing chemistry for hybrid chemical enzymatic synthesis. Synthesis or de novo in suspension culture is the most efficient biotechnological way to produce an organic chemical, provided a suitable strain and a process is available. However, the development of industrial production strains requires massive pathway engineering using a variety of readily available prokaryotic and eukaryotic microorganisms (chemotrophic and phototrophic) for the manufacture of chemicals. This synthetic biology approach needs particular attention. Software tools such as the 'Genome Calligrapher' or 'Genome Partitioner' developed at the ETH Zurich by the group of Beat Christen are important auxiliaries for the advancement of synthetic biology. As discussed earlier, it appears that highly automated screening processes and dedicated software solutions are key for success. Another key aspect is the availability of multiple chassis organisms. It seems appropriate to examine in more detail how this important tool can be better implemented for the benefit of the Swiss economy.

One goal of this paper is to serve as primer for the first SATW Forum 'Biotechnology beyond red biotechnology' in collaboration with SBA and other partners. We also want to reach out and motivate stakeholders to join us in this strategic endeavour to make Switzerland even more competitive.

\section{Acknowledgements}

The authors would like to express their gratitude to Prof. Rebecca Buller (ZHAW) for comments on the manuscript and her excellent inputs for the 'Research and Academia' section. We also thank Dr. Nicholas Shaw (Lonza) for critically reading the manuscript and whose 30 years of experience in the biotech industry were a valuable asset for the refinement of this contribution.

Received: February 23, 2020

[1] P. Pollak, Chimia 1997, 51, 270

[2] https://www.swissbiotech.org/wp-content/uploads/2019/05/Swiss-biotechreport-2019-1.pdf

[3] H.-P. Meyer, W. Minas, D. Schmidhalter, in 'Industrial Biotechnology', Eds. C. Wittmann, J. Liao, Wiley-VCH, 2016, p.3

[4] M. Porter, 'The Five Competitive Forces That Shape Strategy', in Harvard Business Review, 2008, www.hbr.org

[5] Y. Holtzmann, Chem. today 2018, 36, 53

[6] O. Ghisalba, H.-P. Meyer, R. Wohlgemuth, in 'Encyclopedia of Industrial Biotechnology: Bioprocess, Bioseparation, and Cell Technology', Ed. M.C. Flickinger, John Wiley \& Sons Inc, 2010, p. 1.

[7] H.-P. Meyer, E. Eichhorn, S. Hanlon, S. Lütz, M. Schürmann, R. Wohlgemuth, R. Coppolecchia, Catal. Sci. Technol. 2012, doi:10.1039/c2cy20350b

[8] E. Eichhorn, E. Locher, S. Guillemer, D. Wahler, L. Fourage, B. Schilling, PCAS. Adv. Syn. Catal. 2018, 360, 2339

[9] H.-P. Meyer, W. Minas, D. Schmidhalter, in 'Industrial Biotechnology', Vol 4, Eds. C. Wittmann J.C. Liao, Wiley-VCH, Weinheim, 2017, p.3

[10] interpharma, 'Pharma-Markt Schweiz', Ausgabe 2018, www.interpoharma.ch

[11] K.C, Nicolaou, Proc. R. Soc. 2014, 470, 20130690, doi: 10.1098/ rspa.2013.0690.

[12] P. Thesmar, O. Baudoin, J. Am. Chem. Soc. 2019, 141, doi: 10.1021/ jacs.9b09359. 
[13] https://chemistryhall.com/future-of-chemistry-artificial-intelligence/\#How Can_the_Future_of_Chemistry_Be_Defined_by_AI

[14] R. Saleh, A. Bearth. M. Siegrist, "CChemophobia” Today: Consumers' Knowledge and Perceptions of Chemicals', 2019, Wiley Online Library, https://doi.org/10.1111/risa.13375

[15] Evaluate, 'World Preview 2019, Outlook to 2024', https://info.evaluate.com/ rs/607-YGS-364/images/EvaluatePharma World Preview 2019.pdf

[16] B. G. de la Torre, F. Albericio, Molecules 2020, 25, 745, doi: 10.3390/ molecules 25030745 .

[17] R. Patel, 'Green Biocatalysis', Wiley, 2016.

[18] H. P. Meyer, O. Werbitzky, G. A. Signorell, Curr. Org. Chem. 2014, 18, 944

[19] O. Werbitzky, M. Giraud, 'Venoms to Drugs - Venom as a Source for the Development of Human Therapeutics', Chap. 12, Ed. by G. F. King, 2015 RCS Publishing, Cambridge, p. 290.

[20] A. Scott, C\&EN News 2018, vol. 96, 4, 22.

[21] L. Schmitt, C. Schwarz, S. H. J. Smits, WO Patent Appl. No. WO2013057312A1, 2013.

[22] L. Schmitt, C. Schwarz, S. H. J. Smits, EP Patent Appl. No. EP2792686 A1, 2013

[23] C. Kutzner, M. Giuman, WO Patent Appl. No. WO 2019138125 A1, 2019.

[24] J. Flood, Food Secur. 2010, 2, 215.

[25] A. Regalado, 'MITTechnology Review 2015', https://www.technologyreview. $\mathrm{com} / \mathrm{s} / 540136 /$ the-next-great-gmo-debatel

[26] P. M. Waterhouse, M. W. Graham, M. B. Wang, Proc. Natl. Acad. USA 1998 $95,13959$.

[27] S. Dubelman, J. Fischer, F. Zapata, K. Huizinga, C. Jiang, J. Uffman, S. Levine, D. Carson, PLOS ONE 2014, 9, e93155

[28] F. Tenllado, J. R. Diaz-Ruiz, J. Virol. 2001, 75, 12288

[29] F. T. Thammasorn, P. Sangsuriya, W. Meemetta, S. Senapin, S. Jitrakorn, T. Rattanarojpong, V. Saksmerprome, BMC Biotechnol. 2015, 15, 110

[30] A. E. Voloudakis, M. C. Holeva, L. P.Sarin, D. H. Bamford, M. Vargas, M. M. Poranen, F. Tenllado, in 'Methods in Molecular Biology', Chap. 19, Eds. I. Uyeda, C. Masuta, Springer Science+Business Media New York, 2015, p. 255 .

[31] S. Hashiro, M. Mitsuhashi, Y. Chikami, H. Kawaguchi, T. Niimi, H. Yasueda, Appl. Microbiol. Biotechnol. 2019, 103, 8485.

[32] J. L. Kilmer, P. D. Mclaughlin, J.P. H. Arhancet, WO Patent Appl. No. WO2017160600 A1, 2017.

[33] W. J. Blake, D. S. Cunningham, D. Maceachran, WO Patent Appl. No. WO 2016160936 A1, 2016.

[34] http://www.globalengage.co.uk/pgc/docs/PosterMaxwell.pdf

[35] N. Mitter, E. A. Worrall, K. E. Robinson, P. Li, R. G. Jain, C. Taochy, S. J. Fletcher, B. J. Caroll, G. Q. Lu, Z. P. Xu, Nat. Plants 2017, 3, 16207.

[36] A. H. Shakeel, Z. G. Davis, J. T. Frank, S. Zomorodi, P. Pourtaheri, WO Patent Appl. No. WO2019060903 A1, 2019.

[37] a) J. Gosline, M. Denny, M. DeMont, Nature 1984, 309, 551, doi:10.1038/309551a0; b) R. V. Lewis, Acc. Chem. Res. 1992, 25, 9, 392 doi: 10.1021/ar00021a002.

[38] a) S. R. Fahnestock, S. L. Irwin, Appl. Microbiol. Biotechnol. 1997, 47, 23, doi: 10.1007/s002530050883; b) S. R. Fahnestock, L. A. Bedzyk, Appl. Microbiol. Biotechnol. 1997, 47, 33, doi: 10.1007/s002530050884.

[39] F. Teulé, Y.-G. Miao, B.-H. Sohn, Y.-S. Kim, J. J. Hull, M. J. Fraser, R. V. Lewis, D. L. Jarvis, PNAS 2012, 109, 923, doi:10.1073/pnas.1109420109.

[40] a) P. A. Guerette, A. G. T. Miserez, WO Patent Appl. No. WO2014062134 A1, 2014; b) T. Yoshioka, T. Tsubota, K. Tashiro, A. Jouraku, T. Kameda, Nat. Commun. 2019, 10, 1469, doi: 10.1038/s41467-019-09350-3.

[41] a) P-S. Huang, S. E. Boyken, D. Baker, Nature 2016, 537, 320; b) Y. Lin, B. An, M. Bagheri, Q. Wang, J. Harden, D. L. Kaplan, ACS Biomater. Sci. Engin. 2017, 3; c) S. Lin, S. Ryu, O. Tokareva, G. Gronau, M. M. Jacobsen, W. Huang, D. J. Rizzo, D. Li, C. Staii, N. M. Pugno, J. Y. Wong, D. L. Kaplan, M. J. Buehler. Nat. Commun. 2016, 6, 6892, doi:10.1038/ncomms7892.

[42] R. Saleh, A. Bearth, M. Siegrist, Risk Analysis 2019, 39, 2668, doi. org/10.1111/risa.13375.

[43] https://www.firmenich.com/en_INT/company/news/white-biotechnologyambrox.html

[44] E. Eichhorn, E. Locher, S. Guillemer, D. Wahler, L. Fourage, B. Schilling, Adv. Synth. Catal. 2018, 360, 3239, doi: 10.1002/adsc.201800132.

[45] https://www.marketsandmarkets.com/PressReleases/feed-enzyme.asp

[46] O. Thees, V. Burg, M. Erni, G. Bowman, R. Lemm, WSL Berichte 2017, Heft 57, ISSN 2296-3456.
[47] U. T. Bornscheuer, G. Huisman, R. J. Kazlauskas, S. Lutz, J. C. Moore, K. Robins, Nature 2012, 485, 7397.

[48] S. P. Simeonov, J. P. M. Nunes, K. Guerra, V. B. Kurteva, V. A. M. Afonso, Chem. Rev. 2016, 116, 5744-5893.

[49] O. El-Sepelgy, N. Alandini, M. Rueping, Angew. Chem. Int. Ed. 2016, 55, 1360 .

[50] S. K. Ma, J. Gruber, C. Davis, L. Newman, D. Gray, A. Wang, J. Grate, G. W. Huisman, R. A. Sheldon, Green Chem. 2010, 12, 81 .

[51] C. K. Savile, J. M. Janey, E. C. Mundorff, J. C. Moore, S. Tam, W. R. Jarvis, J. C. Colbeck, A. Krebber, F. J. Fleitz, J. Brands, P. N. Devine, G. W. Huisman, G. J. Hughes, Science 2010, 329, 305.

[52] I. V. Pavlidis, M. S. Weiß, M. Genz, P. Spurr, S. P. Hanlon, B. Wirz, H. Iding, U. T. Bornscheuer, Nat. Chem. 2016, http://dx.doi.org/10.1038/ nchem. 2578 .

[53] F. H. Arnold, Angew. Chem. Int. Ed. 2018, 57, 4143, doi:10.1002/ anie. 201708408.

[54] R. Buller, 'Biokatalyse und Biosynthese - Nachhaltige chemische Produktion, Technology Outlook 2019', SATW.

[55] G. Grogan, N. J. Turner, Chem. Eur. J. 2016, 22, 1900.

[56] M. Schober, C. MacDermaid, A. A. Ollis, S. Chang, D. Khan, J. Hosford, J. Latham, L. A. F. Ihnken, M. J. B. Brown, D. Fuerst, M. J. Sanganee, G. D. Roiban, Nat. Catal. 2019, 2, 909.

[57] F. Rudroff, M. D. Mihovilovic, H. Groger, R. Snajdrova, H. Iding, U. T. Bornscheuer, Nat. Catal. 2018, 1, 12.

[58] M. A. Huffman, A. Fryszkowska, O. Alvizo, M. Borra-Garske, K. R. Campos, K. A. Canada, P. N. Devine, D. Duan, J. H. Forstater, S. T. Grosser, H. M. Halsey, G. J. Hughes, J. Jo, L. A. Joyce, J. N. Kolev, J. Liang, K. M. Maloney, B. F. Mann, N. M. Marshall, M. McLaughlin, J. C. Moore, G. S. Murphy, C. C. Nawrat, J. Nazor, S. Novick, N. R. Patel, A. RodriguezGranillo, S. A. Robaire, E. C. Sherer, M. D. Truppo, A. M. Whittaker, D. Verma, L. Xiao, Y. Xu, H. Yang, Science 2019, 366, 1255

[59] P. S. Huang, S. E. Boyken, D. Baker, Nature 2016, 537, 320.

[60] J. D. Holly, T. R. Ward, ACS Central Sci. 2019, 5, 1120.

[61] T. Hayashi, M. Ligibel, E. Sager, M. Voss, J. Hunziker, K. Schroer, R. Snajdrova, R. Buller, Angew. Chem. Int. Ed. 2019, 58, 18535.

[62] S. Studer, D. Hansen, Z. Pianowski, P. Mittl, A. Debon, S. Guffy, B. Der, B. Kuhlman, D. Hilvert, Science 2018, 362, 1285.

[63] T. R. Ward, Acc. Chem. Res. 2011, 44, 47.

[64] M. Jeschek, R. Reuter, T. Heinisch, C. Trindler, J. Klehr, S. Panke, T. R. Ward, Nature 2016, 537, 661.

[65] C. Liao, F. P. Seebeck, Nat. Catal. 2019, 2, 696

[66] T. Hayashi, M. Ligibel, E. Sager, M. Voss, J. Hunziker, K. Schroer, R. Snajdrova, R. Buller, Angew. Chem. Int. Ed. 2019, 58, 18535.

[67] L. Shuai, M. T. Amiri, Y. M. Questell-Santiago, F. Héroguel, Y. Li, H. Kim, R. Meilan, C. Chapple, J. Ralph, J. S. Luterbacher, Science 2016, 35, 329.

[68] S. Wu, Y. Zhou, D. Gerngross, M. Jeschek, T. R. Ward, Nat. Commun. 2019, 10,5060 .

[69] N. Hanik, C. Utsunomia, S. Arai, K. Matsumoto, M. Zinn, Front. Bioeng. Biotechnol. 2019, 7, 301.

[70] R. Buller, K. Hecht, M. Mirata, H.-P. Meyer, in 'Biocatalysis: An Industrial Perspective', Eds. G. de Gonzalo, P. Dominguez, RCS Catalysis Series, 2017, p.3.

[71] A. Debon, M. Pott, R. Obexer, A. P. Grren, L. Friedrich, A. D. Griffiths, D. Hilvert, Nat. Catal. 2019, 2, 740.

[72] M. R. Correro, N. Moridi, H. Schützinger, S. Sykora, E. M. Ammann, E. H. Peters, Y. Dudal, P. F.-X. Corvini, P. Shahgaldian, Angew. Chem. Int. Ed. 2016, 55,6285 .

[73] M. L. Contente, F. Paradisi, Nat. Catal. 2018, 1, 452.

\section{License and Terms}

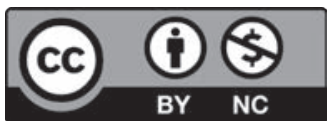

This is an Open Access article under the terms of the Creative Commons Attribution License CC BY_NC 4.0. The material may not be used for commercial purposes.

The license is subject to the CHIMIA terms and conditions: (http:// chimia.ch/component/sppagebuilder/?view=page \&id=12).

The definitive version of this article is the electronic one that can be found at doi:10.2533/chimia.2020.345 